\title{
Ficus subg. Pharmacosycea sect. Pharmacosycea (Moraceae) do Brasil
}

\author{
Ficus (Moraceae) subg. Pharmacosycea sect. Pharmacosycea from Brazil
}

\author{
Leandro Cardoso Pederneiras ${ }^{1,4}$, Victor Peçanha de Miranda Coelho ${ }^{2} \&$ Sergio Romaniuc Neto ${ }^{3}$
}

\begin{abstract}
Resumo
Ficus sect. Pharmacosycea é caracterizada por árvores terrestres, raro hemiepífita, monóicas, geralmente sem raízes adventícias, látex amargo, folhas inteiras, com duas glândulas basais, geralmente um sicônio por axila, ostíolo circular, flores estaminadas e estiletadas dispersas dentro do receptáculo e dois estames. Foram realizadas excursões científicas na Amazônia e na Mata Atlântica, além de consultas a herbários brasileiros, sul e norte-americanos e europeus para a análise taxonômica. No Brasil ocorrem 10 espécies distribuídas nas regiões norte, centro-oeste, sudeste e sul, e raras no nordeste: Ficus adhatodifolia, F. crassivenosa, F. ernanii, F. insipida, F. maxima, F. maximoides, F. obtusiuscula, F. pulchella, F. ulei e F. vermifuga. Dentre estas espécies, F. maximoides está sendo citada pela primeira vez no Brasil e os nomes $F$. ulei e $F$. vermifuga estão sendo novamente utilizados na circunscrição de espécies (eram sinônimos anteriormente). Este presente trabalho também propõe neótipo para Ficus helminthagoga e lectótipo para Pharmacosycea perforata var. angustifolia. Palavras-chave: Amazônia, figueira, Mata Atlântica, Rosales, taxonomia.
\end{abstract}

\begin{abstract}
Ficus sect. Pharmacosycea is characterized by terrestrial trees, monoecious, without adventitious roots, bitter latex, entire leaves, with two basal glands, usually a syconium per axilla, circular ostiole, staminate and styled flowers dispersed in the receptacle and two stamens. Field works were carried out in the Amazon and Atlantic Forest, as well as consultations in herbarium collections in Brazil, United States and Europe. In Brazil there are 10 species mainly in Região Norte, Centro-Oeste, Sudeste and Sul, and rare in Nordeste: Ficus adhatodifolia, F. crassivenosa, F. ernanii, F. insipida, F. maxima, F. maximoides, F. obtusiuscula, F. pulchella, F. ulei and $F$. vermifuga. Among these species, F. maximoides is being cited for the first time in Brazil and $F$. ulei and $F$. vermifuga names are being used in species circunscription again (they were synonymous). The present work also proposes one neotype for Ficus helminthagoga and lectotype for Pharmacosycea perforata var. angustifolia. Key words: Amazonian forest, fig, Atlantic forest, Rosales, taxonomy.
\end{abstract}

\section{Introdução}

Ficus subg. Pharmacosycea (Miq.) Miq. sect. Pharmacosycea (Miq.) Griseb. é caracterizada como árvores terrestres (exceto $F$. crassivenosa W.C.Burger, hemiepífita), de desenvolvimento independente, monóicas, látex amargo, folhas com glândulas basais, geralmente um sicônio por axila, flores estaminadas e estiletadas dispersas no receptáculo e dois estames. Ocorrem nas florestas tropicais das Américas, com ca. 35 espécies, com maior biodiversidade na Cordilheira dos
Andes, principalmente na Colômbia e Ecuador (Pederneiras \& Romaniuc 2012), podendo alcançar altitudes de até $2.500 \mathrm{~m}$.

No Brasil, espécies de Ficus sect. Pharmacosycea foram publicadas inicialmente por Schott (1827), Spix \& Martius (1831) e Miquel $(1848,1853,1867)$ totalizando seis espécies: Ficus adhatodifolia Schott, F. insipida Willd., F. maxima Mill., F. obtusiuscula (Miq.) Miq., F. pulchella Schott e F. vermifuga (Miq.) Miq. Glaziou (1913) listou F. adhatodifolia, F.

\footnotetext{
${ }^{1}$ Jardim Botânico do Rio de Janeiro, DIPEQ, R. Pacheco Leão 915, 22460-030, Rio de Janeiro, RJ.

${ }^{2}$ Instituto Federal de Educação, Ciências e Tecnologia do Triângulo Mineiro, Av. Randolfo Borges Júnior 4000, 38064-300, Univerdecidade, Uberaba, MG.

${ }^{3}$ Instituto de Botânica, Herbário, C.P. 3005, 01031-970, São Paulo, SP.

${ }^{4}$ Autor para correspondência: leandro.pederneiras@gmail.com
} 
obtusiuscula, $F$. pulchella e $F$. vermifuga no Rio de Janeiro e Dewolf $(1964,1965)$ revisou o grupo concluindo quatro espécies para o Brasil: F. insipida, F. maxima, F. obtusiuscula e F. pulchella. Os estudos mais modernos foram realizados por Berg et al. (1986), Carauta (1989), Carauta \& Diaz (2002) e Berg \& Villavicencio (2004) que incluíram dentre as espécies citadas, F. piresiana Vázq.Avila \& C.C.Berg. Pederneiras et al. (2012), por fim, citaram F. ernanii Carauta et al. e F. ulei Rossberg. Este trabalho teve como objetivo descrever as espécies de Ficus sect. Pharmacosycea ocorrentes no Brasil, construir chave taxonômica para as espécies, incluindo informações sobre distribuição geográfica, habitat, materiais examinados, comentários e ilustrações.

\section{Material e Métodos}

Foram realizadas excursões para coleta de material botânico em diversas partes do país, principalmente na Amazônia e Mata Atlântica. Foram visitados os herbários do Brasil, Colômbia, EUA, Europa e Venezuela (B, BM, C, COL, EAFM, F, G, GH, GUA, HUA, IAN, INPA, JAUM, K, M, MG, MIRR, MY, NY, P, PORT, R, RB, SP, UFACPZ, US, VEN). Também foram realizadas consultas on line nos herbários $\mathrm{A}$, BR, C, MO, S e U. Dentre todos estes herbários, destacamos a visita ao da Universidade de Bergen, Noruega, uma das maiores coleções de Moraceae do mundo e onde o especialista Dr. C.C.Berg trabalhou. A nomenclatura morfológica foi examinada com base em Radford (1987).

\section{Taxonomia}

Ficus subg. Pharmacosycea sect. Pharmacosycea (Miq.) Griseb., Fl. Brit. W. I.: 150. 1864. $\equiv$ Pharmacosycea Miq., London J. Bot. 6: 525 (1847); 7: 64 (1848). Lectótipo: Ficus maxima Mill.; designado por Corner, Gard. Bull. Singapora 17: 406 (1959).
Árvores terrestres (raro hemiepífita: Ficus crassivenosa), monóicas; casca vermelhoacastanhada a acinzentada, macia, lisa a semirrugosa; raízes tabulares na base do tronco; látex branco, amargo. Ramo terminal com estípula verde a verde-amarelado, epiderme inteira ou descamante, lenticelas ao redor da parte distal; duas escamas do botão lateral, cônicas, imbricadas, a mais externa cuculada. Folha com lâmina de margens planas, coriácea ou cartácea, lados simétricos; venação broquidódroma a eucampdódroma; nervura secundária basal alcançando a $1 / 4$ a $1 / 16$ do compr. da lâmina; nervuras intersecundárias compostas e paralelas; nervuras terciárias reticulares, ortogonal; glândulas duas, na axila da nervura secundária basal; pecíolo canaliculado, raramente plano, estriado, epiderme inteira ou descamante, lenticelas presentes ou não. Sicônios solitários, raramente geminados, axilares; hipobráctea cuculada, caduca, raramente persistente; pedúnculo presente ou receptáculo séssil; epibrácteas três, livres, raramente conadas na base, cuculada, deltóide, inteiras, raramente bipartidas, persistentes a caducas; receptáculo verde, globoso, obloide, piriforme ou elipsoide, ápice crateriforme, aprofundado, agudo, arredondado ou plano; brácteas laterais geralmente ausentes; máculas verde-claras; ostíolo circular com orobrácteas deltoides, imbricadas; flores estiletadas e estaminadas dispersas no receptáculo. Flores com tépalas membranáceas; estilete lateral; flor longo-estiletada sésseis a subsésseis; estigma profundamente bífido; flor curto-estiletada pedunculada, estigma peltado, tépalas livres, quatro; flores estaminadas pedunculadas com 2 ou 4 brácteas, perigônio com metade inferior conata, 4 tépalas; pistilódio filiforme; estames geralmente 2, raramente 1 ou 3, anteras ditecas. Fruto tipo noz, alva a amarelada. Semente com presença de endosperma e embrião curvo.

\section{Chave taxonômica para as espécies de Ficus sect. Pharmacosycea do Brasil}

1. Pecíolo sem descamação da epiderme ......................................................................................... 2

2. Receptáculo entre $1,2-2,5 \mathrm{~cm}$ de diâm., lâmina com ápice levemente acuminado, agudo, obtuso ou arredondado

3. Número de nervuras secundárias acima de 17 pares ........................................................ 4

4. Lâmina entre 16-30 cm de compr., ápice agudo ................................... Ficus insipida

4'. Lâmina entre 8-12 cm de compr., ápice obtuso a arredondado ...... Ficus crassivenosa

3'. Número de nervuras secundárias até 17 pares ............................................................. 5

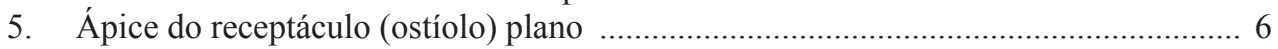


6. Receptáculos híspidos, escabros Ficus ernanii

6'. Receptáculos glabros, lisos Ficus adhatodifolia

5'. Ápice do receptáculo (ostíolo) crateriforme Ficus vermifuga

2'. Receptáculo até $1,2 \mathrm{~cm}$ de diâm., lâmina com ápice acuminado a caudada ... Ficus obtusiuscula

1'. Pecíolo com descamação da epiderme 7

7. Pedúnculo séssil-1,5 mm de compr. ......................................................................... Ficus ulei

7'. Pedúnculo entre 3-20 $\mathrm{mm}$ de compr.

8. Estípula de $3-6 \mathrm{~cm}$ de compr. Ficus maximoides

8'. Estípula de $1,5-2,5 \mathrm{~cm}$ de compr. 8

9. Nervuras secundárias $19-27$ pares, se divergindo da principal a cada $3-8 \mathrm{~mm}$ Ficus pulchella

9'. Nervuras secundárias 8-16 pares, se divergindo da principal a cada 10-27 mm Ficus maxima

1. Ficus adhatodifolia Schott ex Spreng. Syst. Veg., editio decima sexta 4 (App.): 409. 1827 $\equiv$ Pharmacosycea adhatodifolia (Schott) Miq., London J. Bot. 7: 70. 1848. Tipo: Brasil, Rio de Janeiro, 1817-1821, Schott s.n. (B!). Fig. 1a = Ficus officinalis L.B.Sm., Rhodora 50: 132 . $1948 \equiv$ Ficus perforata (Miq.) Chod., Bull. Herb. Boissier, ser. 2, vol. 3: 350. $1903 \equiv$ Ficus perforata (Miq.) Miq., Ann. Mus. Bot. Lugduno-Batavi 3: $300.1867 \equiv$ Pharmacosycea perforata Miq., London J. Bot. 7: 68. 1848. Tipo: Brasil, Rio de Janeiro, 1821-1823, Graham s.n. (K442906!).

Árvores $10-30 \mathrm{~m}$ alt. Ramo terminal com estípula verde, 3-4 cm compr., 3-5 $\mathrm{mm}$ de larg. Folha com lâmina esverdeada 15-20 × 8-10 cm, elíptica a ovada, ápice agudo, base aguda, às vezes levemente cordada, cartácea; face abaxial lisa, pubérula nas proximidades da nervura principal; face adaxial lisa, pubérula; nervura principal alcançando o ápice, divergindo em nervuras secundárias a cada 9-13 mm por lado; nervura secundária mediana 3,5-7 cm compr., 14-16 pares, arqueadas, curvadas no ápice, unindo a nervura secundária supradjacente em ângulo reto, não formando nervura intramarginal, $65-70^{\circ}$ de divergência da principal; pecíolo 4-6 cm compr., 2-3 mm larg., canaliculado, glabro, epiderme não-descamante. Sicônios solitários; hipobráctea 2-4,5 $\times 2 \mathrm{~mm}$, glabra, caduca; pedúnculo verde a avermelhado $1-1,5 \mathrm{~cm}$ de compr., 1-2 mm de larg., sobressaindo levemente ao eixo principal, glabro; epibrácteas $2 \mathrm{~mm}$, ápice agudo, ambas as faces glabras, persistentes; receptáculo verde, $1,5-2 \mathrm{~cm}$ de diâm. (tamanho natural 1,5-3), esferóide, ápice arredondado a obtuso, face externa pubérula, face interna glabra; parede do receptáculo $2-3 \mathrm{~mm}$ de larg.; brácteas laterais ausentes; máculas verde- claras; ostíolo até $3 \mathrm{~mm}$ de diâm. externamente; orobrácteas superiores $0,7-1 \times 0,6-1 \mathrm{~mm}$, persistentes. Flores com tépalas rosadas, 1-2,5 $\times 0,5-1 \mathrm{~mm}$, pubérulas na borda do ápice; flor longo-estiletada $4 \mathrm{~mm}$ de alt., estigma $0,7-0,9 \mathrm{~mm}$ cada lado; flor curto-estiletada 4-7 mm, estigma 0,1-0,3 $\mathrm{mm}$; flor estaminada 4-6 $\mathrm{mm}$, perigônio ca. $1 \mathrm{~mm}$, ápice ca. $1 \mathrm{~mm}$, pistilódio ca. $0,3 \mathrm{~mm}$, estames ca. 2-2,5 mm; brácteas laterais $3-5 \mathrm{~mm}$. Infrutescência verde-clara.

Ocorre principalmente no Brasil, na Floresta Atlântica e nas matas de galeria do cerrado, e também nos limites com a Argentina, Bolívia e Paraguai, em altitudes de 10-1.100 m.

Material examinado: BRASIL. Sem localidade, 18161821, A.Saint-Hilaire 781 (P); Collib, I.1832, Riedel 1009 (US); Capella dos Botelhos, VIII.1864, Glaziou 1099 (P); 1863-1866, J.E.B.Warming 1893 (P); s.d., Ferreira (P); s.d., Richard (P); s.d., Gaudichaud 1218 (P). BAHIA: Cachoeira-Roncador, Vale dos Rios Paraguaçu e Jacuipe, VIII.1980, Grupo Pedra da Cavalo 542 (SP, RB); Coribe, Estrada São Félix do Coribe-Coribe, 20.VII.2009, M.M. Saavedra 996 (RB, SP); Ibotirama, IX.1974, AndradeLima 7821 (SP, INPA); Uruçuca, Fazenda Novo Horizonte, X.1997, R.H.R.Sambuichi 134 (GUA). BRASÍLIA: Bacia do Rio São Bartolmeu, 24.III.1981, E.P.Heringer $6514(\mathrm{~K})$; Bacia do Rio São Bartolmeu, 30.VI.1982, B.A.S.Pereira 307 (US, K); Reserva Ecológica IBGE, 12.V.1983, B.S.A.Pereira 505 (GUA, F); Fazenda Água Limpa/UnB, Córrego da Onça, 15.XII.1994, B.M.T.Walter 2310 (SP, INPA); Rio das Salinas, 13.VIII.1981, J.H.Kirkbride 4334 (US); Bacia do Rio São Bartolmeu, 9.X.1980, E.P.Heringer 5561 (US, K); Rio Torto, ca. $10 \mathrm{~km} \mathrm{~N}$ of Brasília, 6.VII.1966, H.S.Irwin 18063 (RB, F, US, GH, K). ESPÍRITO SANTO: Dores do Rio Preto, Três estados, 12.X.2000, E.A.Costa 84 (RB). GOIÁS: Cayaponia e Piranhas, 6.IV.1958, A.Lima 3017 (RB, K); Caldas Novas, $13 \mathrm{~km}$ due WSW of city of Caldas Novas, 19.XII.1974, E.P.Heringer 14100 
(SP, US, K); Campinaçu, Córrego Laginha,10.X.1991, T.B.Cavalcanti 944 (SP, CEN, GUA); Colinas do Sul, Bacia de inundação da UHE Serra da Mesa, 12.XII.1991, B.M.T.Walter 1032 (SP, CEN); Crixás, 21.X.1992, V.L.G.Klein 10(RB); Niquelândia, 29.I.1997, B.M.T.Walter 3699 (SP, CEN). MATO GROSSO: Novo Mundo, 4. II.2008, D.Sasaki 2183 (K); Rosário do Oeste, Marzagão, Rio Cedral, 22.X.1995, G.Hatschbach 63995 (SP, MBM, RB); Xavantina, 22.VIII.1961, J.A.Ratter 439 (P, K); MATO GROSSO DO SUL: Bataiporã, Várzea do Rio Samambaia, 27.X.1986, U.Pastore 144 (RB); Bonito, margens do Rio Formosinho, 13.IV.2001, R.Constantino 96 (GUA); Camapuã, 4.XI.1979, F.C.Silva 122 (US, K); Cerradão, Porto Murtino, 26.IX.1996, S.Bridgewater 359 (K); MINAS GERAIS: 1977, M.B.Ferreira 706 (RB); Nova Ponte, Área 3, 20.X.1987, Pedralli 1213 (RB); Araguari, Rodovia GO-050, próximo ao Rio Araguari, 6.XI.1991, G.Hatschbach 55816 (SP, MBM); Araxá, Barreiro, no Parque do Grande Hotel, 13.V.2000, B.E.Diaz 277 (RB); Carangola, Serra da Araponga, 12.X.1990, L.S.Leoni 1274 (GUA); Itapagipe, vicinal Campina Verde, 25.V.2007, L.F.M.Coelho 12 (RB); Montes Claros, bairro Edgar Pereira, 2.VI.2012, P.P.Souza 324 (SP); VI.1949, H.Paula (SP); Ouro Preto, Gandarela, 31.II.1884, A.Glaziou 15431 (P, K); Rio Doce, Estrada entre Rio Doce e o distrito de Santana do Deserto, 16.X.1997, I. Cordeiro 1661 (SP); Viçosa, Mata do Paraiso, margem direita da estrada, 16.V.2007, P.P.Souza 177 (RB, SP); Campus UFV, 14.XII.2010, G.Pelissari 189 (SP); Paula Cândido, 7. XII.1993, M.F.Vieira 813 (SP); Escola Superior de Agricultura, 5.II.1934, J.G.Kuhlmann 1640 (RB, US); 24.V.1930, Y.Mexia 4740 (F, US, GH, K); Escola Superior de Agricultura, 5.XI.1934, J.G.Kuhlmann (SP). PARÁ: Paraná do Ricardo, 28.VIII.1934, B.A.Krukoff 5916 (RB, F, US, GH, K). PARANÁ: Parque Nacional do Iguaçu, 11.XII.1966, J.C.Lindeman 3514 (RB, GH); Cerro Azul, 2.VIII.1966, J.C.Lindeman 2131 (US, K); Rio Ponta Grossa, 24.X.1959, G.Hatschbach 6386 (GUA, K); Foz do Iguaçu, Parque Nacional de Foz do Iguaçu, 6.XII.1992, S.A.Nicolau 562 (SP); Guaraqueçaba, 27.X.1971, G.Hatschbach 27591 (K); Guaratuba, Garuva, 19. IX.1959, G.Hatschbach 6314 (K); Ibipora, 20.VIII.1997, F.A.Cloclet (K); Iporã, Fazenda Doralice, 29.VIII.1997, P.F.Alves (SP, FUEL); Jaçarehy, 14.VII.1914, P.Dusén 15283 (F, GH, P, K); Londrina, Fazenda Figueira-Paiquerê, 27.VI.2003, M.C.Lovato 246(SP); Maringá, 12.VI.1980, A.Ide 1 (RB); Sete Quedas, Guaíra, 14.XI.1963, E.Pereira 7884 (RB); Telêmaco Borba, Fazenda Monte Alegre, 11.X.1995, M.R.C.Paiva 24 (SP, K). RIO DE JANEIRO: Angra dos Reis, Ilha Grande, Praia do Demo, 24.XI.2002, R.Scheel-Ybert 285 (GUA); Angra dos Reis, Ilha Grande, Reserva Biológica Estadual da Praia do Sul, 26.XI.1991, C.A.L. de Oliveira 508 (GUA); Itatiaia, Penedo, na margem esquerda do Rio das Pedras, 23.III.2002, P.P.Souza 145 (RB); Magé, Santo Aleixo, 1.XI.2010, L.C.Pederneiras 610, 616 (SP); Nova Friburgo, estrada para Lumiar, 18.X.1977, J.P.P.Carauta 2705 (RB, GUA, SP, INPA, K); Nova Iguaçu, Rebio Tinguá, 13.XI.2001,
H.C.Lima 5904 (RB); Paraty, Ilha do Algodão, 12.IV.1989, E.L.Jacques 96 (RB); Ponta Negra, 8.VI.1994, R.Reis 151 (RB, GUA); Laranjeiras, 7.XII.1993, T.Konno 374 (RB); Trindade, 8.XI.1991, R.Marquete 439 (RB); Trindade, Praia de Fora, 12.IV.1991, L.C.Giordano 1053 (RB); Rio Corisco, 29.VI.1993, R.Marquete 1085 (RB); Trilha da serra, 28.IX.1996, R.Mello-Silva 1250 (RB); Paraty, Rio dos Meros, 30.VIII.1994, L.C.Giordano 1701 (RB, GUA); Rio dos Meros 21.VIII.1995, L.C.Giordano 2014 (RB, GUA); Parati-Mirim, 17.VI.1993, J.P.P. Carauta 6806 (RB, GUA); Petrópolis, Fazenda Boa Esperança, 20.VII.1978, J.P.P.Carauta 3000 (RB, GUA); 21.IV.1971, L.E.Mello-Filho 3103 (US, P); Resende, Rio das Pedras, 13.II.2001, P.P. Souza 91 (RB); Rio de Janeiro, Parque Estadual da Pedra Branca, 5.III.2004, A.Solórzano 18 (RB); Estação Biológica, 16.I.1963, J.P.P.Carauta 168 (GUA, IAN, K); Ilha da Marambaia, 17.VII.2000, L.F.T.Menezes 594 (RB); Vidigal, 31.X.1927, Pessoal do Horto Florestal 704 (RB); 22.VII.2012, L.C.Pederneiras 752 (SP); Paineiras, 28.V.1867, A.Glaziou 764 (P); GáveaSão Conrado, 10.IV.1947, A.P.Duarte 970 (RB); Alto da Boa Vista, 8.XI.2004, C.A.L. de Oliveira 2428 (GUA); Estrada Dona Castorina, 19.VIII.1980, J.P.P.Carauta 3523 (GUA, SP, RB, F); Estrada das Canoas, 28.V.1958, Liene 3803 (RB); Rocinha - Alto da Gavea, 24.III.1959, A.P.Duarte 4644 (RB); Alto da Boa Vista, 22.VI.1959, A.P.Duarte 4867 (RB, K); Estrada da Vista Chinesa, 20.XII.1991, J.P.P. Carauta 6815 (RB, GUA); Parque Municipal Ecológico da Prainha, 29.X.2003, J.M.A.Braga 7225 (RB, RB, K, MBM, NY, SP); Capela Mayrink, 27.XI.1977, J.P.P.Carauta (RB, SP); Horto Florestal, 22.XII.1926, Pessoal do Horto Florestal (RB, SP); Vista Chinesa, 5.X.1927, Pessoal do Horto Florestal (RB, SP); Gávea, Volta dos Coqueiros, Vidigal, 31.X.1927, Pessoal do Horto Florestal (SP, RB); Santa Maria Madalena, Estrada da Morumbeca, 16.II.1978, J.P.P.Carauta 2819 (RB); Silva Jardim, Trilha da pelonha, 16.VIII.1995, Farág 83 (RB); Distrito de Imbaú, 15.V.2004, A. G.Christo 400 (RB); Trilha do Morro do Calcario, 16.I.1993, H.C.Lima 4604 (K, RB, SP);Valença, perto da margem do Paraíba, 5.IX.1979, J.P.P.Carauta 3206 (RB); Araras - Petrópolis, 25.II.1974, G.Martinelli 218 (RB, GUA); Gaudchaud 1085 (P); entre Macuco e Santa Maria Madalena, 26.IX.1964, E.Santosa 2042 (K). RIO GRANDE DO SUL: Santa Maria, Três Barras, 13.I.2010, R.Zachia 5945 (SP). SANTA CATARINA: Brusque, 15.XII.1949, H.P.Velloso 153 (RB); Araquari, Ilha dos Papagaios, 14.IV.2005, W.S.Mancinelli 228 (SP); Blumenau, Nova Russia, 25.VI.2009, L.F.M.Coelho 51 (RB); 25.VI.2009, L.F.M.Coelho 53 (RB); Bairro Encanto, 28.VI.2011, L.F.M.Coelho 61 (RB); Botuverá, Cinema, 6.IV.2010, J.L.Schmitt 1913 (RB, FURB); Garuva, Três Barras, 28.XI.2003, F.C.S.Vieira 152 (SP); Quiriri, 6. II.2005, F.C.S.Vieira 813 (SP); São Francisco do Sul, 7. XI.1957, P.R.Reitz 5627 (GUA); Guabiruba, Aymoré, 28.X.2009, A.Stival-Santos 1059 (RB); Ibirama, 21. IX.1956, P.R.Reitz 3677 (GUA); Ilha de Santa Catarina, 1832-1833, Gaudichaud 288 (P); Itajaí, 14.IV.1955, 

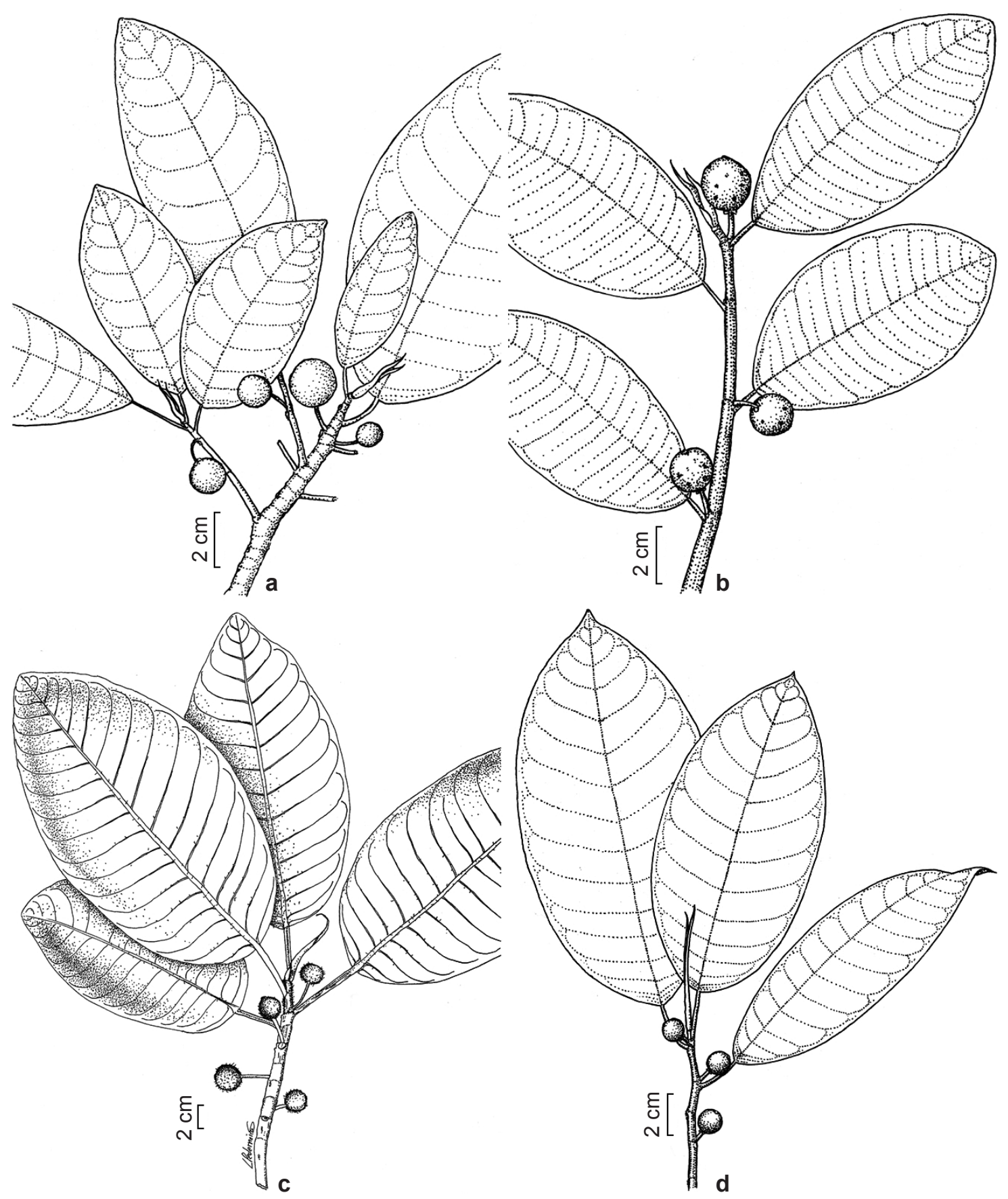

Figura 1 - Ramo com folhas, sicônios e estípulas - a. Ficus adhatodifolia; b. Ficus crassivenosa; c. Ficus ernanii; d. Ficus insipida.

Figure 1 - Twig with leave, syconia and stipules - a. Ficus adhatodifolia; b. Ficus crassivenosa; c. Ficus ernanii; d. Ficus insipida. 
R.M.Klein 1269 (GUA, US); 20.XI.2009, A.Stival-Santos 1273 (SP); Morro da Ressacada, 14.X.1955, R.M.Klein 1690 (GUA, US); São Francisco do Sul, Ilha Araujo de Dentro, 6.VIII.2007, J.Meirelles 56 (SP). SÃO PAULO: Agudos, 25.V.1994, J.Y.Tamashiro 122 (SP, SPF); Fazenda da Cia. Cervejaria Brahma, 27.X.1995, M.E.S.Paschoal 1580 (SP); Fazenda Monte Alegre, Mata da Copaíba, 13.XI.2001, M.E.S.Paschoal 2629 (SP); Apiaí, entorno do PETAR, 25.II.2011, L.C.Pederneiras 664 (SP); Bragança Paulista, Mato Dentro, 4.VI.1946, M.Kuhlmann 1366 (SP); Cananéia, Parque Estadual da Ilha do Cardoso, Morro de Ipanema, 4.XII.1985, I.C.C.Macedo 65 (SP); Ilha do Cardoso, 20.II.2002, E.R. Castro 99 (SP, HRCB); Ilha do Cardoso, 11.III.1982, F.Melo 309 (SP); Ilha do Cardoso, Rio Cachoeira Grande, 25.X.1989, I. Cordeiro 574 (SP); Ilha do Cardoso, Trilha nova da captação - Ipanema, 25.IV.1989, S.Romaniuc Neto 794 (SP); Ilha do Cardoso, Ponte do Rio Perequê, 17.IV.1990, P.Martuscelli 1018 (SP); Capão Bonito, Reserva de Intervalos, 26.X.1999, R.A.S.Pereira 85 (SP); Caraguatatuba, Parque Estadual da Serra do Mar, Núcleo Caraguatatuba, 9.IX.2000, R.S.Bianchini 1449 (SP, SPSF); 16.III.2006, A.Oliveira 2084 (RB); Cássia dos Coqueiros, 9.XI.1994, L.S.Kinoshita 135 (SP); 9.XI.1994, L.S.Kinoshita 136 (SP); Castilho, oeste de Andradina, 20.IX.1998, E.Melo 2491 (SP, HUEFS); Cosmópolis, 18 km de Campinas, 5.XI.2000, H.M.Souza (RB); Eldorado, Parque Estadual de Jacupiranga, 18.V.1994, I.Cordeiro 1434 (SP); Cachoeira do Sapatu, 5.IX.1995, V.C.Souza 9164 (SP); Garça, Rio Vigilância, 20.VII.2008, L.F.M.Coelho 31 (SP, SPFR); Ibiúna, Bairro do Vargedo, Morro dos Pereiras, 27.V.1989, S.Romaniuc Neto 980 (SP); Iguape, Reserva Ecológica Juréia-Itatins, 13.XII.1990, M.P.Costa 12 (SP); Estação Ecológica Juréia-Itatins, Serra da Juréia, Caminho do Imperador, 12.VII.1992, E.A.Anunciação 162 (SP, SPSF); Ilhabela, Parque Estadual da Serra do Mar, Trilha da Água Branca, 16.XI.2001, J.B.Baitello 1756 (SP, SPSF); Iporanga, Bairro da Serra, Sítio Novo, 23.II.2011, L.C.Pederneiras 659 (SP); Lençois Paulista, Lençóis Paulista - Águas de Santa Bárbara, 12.VI.1995, J.Y.Tamashiro 1093 (SP); Magda, Fazenda São Francisco, 19.IV.2005, L.R. Mendonça-Souza 42 (SP); Mamparra, Reserva Florestal Carlos Botelho, 15.II.1995, P.H.Miyagi 473 (SP); Mogi das Cruzes, Parque Municipal da Serra do Itapety, 14.X.1992,Tomasulo 310 (SP); Reserva Biológica e Estação Experimental de Mogi-Guaçu, 11.VI.1992, S.Romaniuc Neto 1299 (SP); Monte Alegre do Sul, Bairro do Lambedor, 23.VII.1949, M.Kuhlmann 1830 (SP); Olímpia, Termas dos Laranjais, 14.I.2007, R.A.S.Pereira 146 (SP, SPFR); Paranapanema, Estação Ecológica, Palmital, 31.I.2008, R.Ciello-Filho 634 (SPSF); Pariquera-Açu, Estação Experimental do IAC, 12.II.1995, N.M.Ivanauskas 23 (SP); Pedreira, Estrada Amparo-Pedreira, 5.IV.1993, S.Romaniuc Neto 1362 (SP, F); Peruíbe, Estação Ecológica Juréia-Itatins, Cachoeira do Paraíso, 12.XII.2010, L.C.Pederneiras
651 (SP); Estrada do Costão, 10.VIII.2010, L.C.Pederneiras 568 (SP); Estrada do Costão, em frente ao Rio Preto, 12.VIII.2010, L.C.Pederneiras 569 (SP); Pindamonhangaba, Fazenda São Sebastião do Ribeirão Grande, 18.VII.1999, S.A.Nicolau 1753 (SP); Piracicaba, Mata do Dois Córregos, 6.VII.1993, K.D.Barreto 837 (SP); Ribeirão Grande, Parque Intervales, 31.II.2006, R.A.S.Pereira 134 (SP, SPFR); Ribeirão Preto, margem do Ribeirão do Sertãozinho, 23.VIII.2007, R.A.S.Pereira 150, 151 (SP, SPFR, RB); Roseira, ca. 5-10 km da margem direita do Rio Paraíba do Sul, 20.I.1995, S.Romaniuc Neto 1409 (SP); Salesópolis, Bairro dos Freires, Estrada Contorno da Barragem, 13.VII.2007, R.A.Costa 35 (SP); São Vicente, Parque Estadual XixováJapuí, 31.X.2003, J.A.Pastore 1274 (SP, SPSF); Serra de Juquiá, 10.IX.1991, H.Lorenzi (SP); Serra Negra, Alto da Serra, 22.XI.1991, F.Barros 2351 (SP); Sete Barras, Fazenda Intervales, Base Saibadela, Trilha do rio, 8. IV.1994, R.J.Almeida-Scabbia 211 (SP); Tucuruvi, Barro Branco, 8.X.2003, L.A.Couto 116 (SP); Ubatuba, entre Praia Vermelha e Itamambuca, 6.XII.2004, L.R.Mendonça 23 (SP); Picinguaba, Estrada da Almada, 31.III.2005, R.A.S.Pereira 108, 109 (SP); Trilha da Casa da Farinha, 30.I.1996, H.F.Leitão-Filho 34715 (SP); Ilha Anchieta, 6.II.1996, H.F.Leitão-Filho 34837 (SP, UEC); Ilha Vitória, litoral Norte, 1.IV.1965, J.C.Gomes 2689 (SP).

Ficus adhatodifolia possui folha glabra, sicônio solitário, receptáculo com ápice arredondado. Esses dados diferem de F. obtusiuscula (sicônio geminado), de $F$. ernanii (folha híspida) e $F$. vermifuga (ápice crateriforme), espécies simpátricas e semelhantes a $F$. adhatodifolia. Dewolf (1965) considerava $F$. adhatodifolia um sinônimo de $F$. insipida, o que foi seguido por Carauta (1989), mas a primeira tem um receptáculo com região ostiolar arredondado a obtuso ( $v s$. subapiculado) e 14-16 pares de nervuras secundárias (vs. 19-27).

2. Ficus crassivenosa W.C.Burger, Phytologia 26(6): 424. 1973. Tipo: Costa Rica, Hacienda Santiago, adjacente to east side of La Selva, near Puerto Viejo, Sarapiqui, Heredia Province, 29.V.1973, G.S.Hartshorn 1238 (F1721187!, isótipo: F1854142!, CR).

Fig. $1 \mathrm{~b}$

Ficus piresiana Vázq.Avila \& C.C.Berg, Acta Amazônica 14 (1/2) suppl.: 207-209. 1986 [1984, publ. 1986]. Tipo: Brasil, Pará, Belém, 10.X.1952, J.M.Pires 4335 (IAN!, isótipo RB!, NY!, US!)

Árvores $12-50 \mathrm{~m}$ de alt. Ramo terminal com estípula 1,5-4 cm de compr., 3-5 $\mathrm{mm}$ de larg. Folha com lâmina 8-12(19) × 4-6(10,5) $\mathrm{cm}$, elíptica, ápice obtuso a arredondado, base obtusa a cuneada, coriácea; face abaxial lisa a levemente verrucosa, pubérula; face adaxial 
lisa, glabra; venação broquidódroma; nervura principal alcançando o ápice, divergindo em nervuras secundárias a cada 2-6(8) $\mathrm{mm}$ por lado; nervuras secundárias medianas 1,5-3(5) cm compr., 14-24(40) pares, retilíneas a arqueadas, unindo a nervura secundária superadjacente em ângulo obtuso, formando nervura intramarginal, $70-90^{\circ} \mathrm{de}$ divergência da principal; pecíolo $1-3 \mathrm{~cm}$ compr., 1,5-2,5 mm larg., canaliculado, glabro, epiderme não-descamante, lenticelas na parte adaxial. Sicônios solitários; hipobráctea ca. $2 \mathrm{~mm}$ de compr., ambas as faces glabras, caduca; pedúnculo $4-10(20) \times$ $1,5-2 \mathrm{~mm}$, sobressaindo ao eixo principal, minuta e esparsamente pubérulo (tricomas ferrugíneos); epibrácteas ca. $3 \mathrm{~mm}$, ápice agudo, ambas as faces glabras, persistentes; receptáculo verde, $1,2-2 \mathrm{~cm}$ de diâm. (ao natural ca. 3,5 cm), esferoide, ápice arredondado, face externa pubérula (tricomas alvos), face interna glabra; parede lateral $1,5-2 \mathrm{~mm}$ de larg.; brácteas laterais ausentes; ostíolo $1 \mathrm{~mm}$ de diâm. externamente, $2 \mathrm{~mm}$ de diâm. internamente; orobrácteas superiores ca. $1 \mathrm{~mm}$ de compr., caducas. Flores com tépalas alvas, $1-2 \times 0,2-0,4 \mathrm{~mm}$, glabras; flor longo-estiletada, ca. $5 \mathrm{~mm}$ de alt., estigma ca. 1 $\mathrm{mm}$ cada lado; flor curto-estiletada 5-6 $\mathrm{mm}$, estigma ca. $0,2 \mathrm{~mm}$; flores estaminadas $8-9 \mathrm{~mm}$, perigônio ca. 2,5 mm, ápice ca. $1 \mathrm{~mm}$, pistilódio ca. $0,2 \mathrm{~mm}$, estames 3-4 mm; brácteas laterais $4-5 \times 0,1-0,4$ $\mathrm{mm}$. Infrutescência verde-amarelada.

Ocorre na América Central, da Costa Rica até o Panamá; e na América do Sul, entre o norte do Brasil até a Bolívia, nas bordas da bacia amazônica; nas florestas úmidas de baixa elevação, em altitudes de $60-1.000 \mathrm{~m}$.

Material examinado: BRASIL. ACRE: Porto Acre, 27.IV.2010, H.Medeiros 566 (UFACPZ). AMAZONAS: Cururú, Rio Ayari, 25.X.1928, Luetzelburg 22716 (R); Jutica, Rio Uaupés, 28.XI.1928, Luetzelburg 23958 (R); Tacira, Rio Papori, Cachoeira, 6.XII.1928, Luetzelburg 23838 (R). PARÁ: Belém, Útinga, 19.VIII.1925, J.G.Kuhlmann 2 (RB); 5.XI.1945, J.M.Pires 576 (IAN); Estrada do Cafezal, Trilha do Igarapé Catu, Mocambo, 19.X.2011, L.C.Pederneiras 680 (IAN, SP); 10.X.1952, J.M.Pires 4335 (IAN, US, NY).

Analisando o material coletado em Belém, Pará, junto com coleções de herbário, foi levantada a hipótese de que as nervuras intersecundárias podem adquirir o mesmo calibre das secundárias quando alcançam a nervura intramarginal causando variação no número de pares nesta espécie. As espécimes da Costa Rica, por exemplo, possuem menos nervuras secundárias talvez por possuir folhas um pouco mais largas. Estudos de ontogenia da folha seriam necessários para confirmar este desenvolvimento.
3. Ficus ernanii Carauta, Pederneiras, P.P. Souza, A.F.P. Machado, M.D.M. Vianna, \& Romaniuc, Albertoa, Série Urticineae (36): 277-284. 2012. Tipo: Brasil, Rio Grande do Sul, entre Forquilhas e Três Cachoeiras, estrada Osório-Torres, BR 101, 27.II.2003, B.Ernanii Diaz 611 (R!). $\quad$ Fig. 1c

Árvores de ca. $20 \mathrm{~m}$ alt. Ramo terminal com estípula verde, 3-5 cm compr., 3-5 mm de larg.; face esterna híspida; face interna glabra. Folha com lâmina 10-22 × 5-10 cm, elíptica a levemente ovada, ápice acuminado a agudo, base rondada a obtusa, cartácea; face abaxial escabra, híspido; face adaxial escabro, híspido; nervura principal alcançando o ápice, divergindo em nervuras secundárias a cada 9-13 mm por lado; nervuras secundárias medianas 3,5-7 cm compr., 10-15 pares, arqueadas, curvadas no ápice, unindo a nervura secundária supradjacente em ângulo reto, não formando nervura intramarginal, $65-70^{\circ} \mathrm{de}$ divergência da principal; pecíolo $2-4 \mathrm{~cm}$ compr., 2-3 mm larg., canaliculado, híspido, epiderme não-descamante. Sicônios solitários; hipobráctea $2-4 \times 2 \mathrm{~mm}$, caduca; pedúnculo $1-1,5 \mathrm{~cm}$ de compr., 1-2 mm de larg., sobressaindo levemente ao eixo principal, pubérulo; epibrácteas $1-1,5 \mathrm{~mm}$, ápice acuminado; receptáculo verde, $0,6-1,7 \mathrm{~cm}$ de diâm., esferóide, ápice arredondado a obtuso, face externa híspida, face interna híspida; parede do receptáculo 2-3 $\mathrm{mm}$ de larg.; brácteas laterais ausentes; máculas verde-claras; ostíolo $3 \mathrm{~mm}$ de diâm. externamente; orobrácteas superiores ca. 1 $\times 1 \mathrm{~mm}$. Flores com tépalas rosadas, $1-2,5 \times 0,5-1$ $\mathrm{mm}$, pubérulas na borda do ápice; flor longoestiletada $1,5-2 \mathrm{~mm}$ de alt., estigma $0,7-0,9 \mathrm{~mm}$ cada lado; flor curto-estiletada $4-7 \mathrm{~mm}$, estigma $0-1-0,3 \mathrm{~mm}$; flor estaminada ca. $2 \mathrm{~mm}$, perigônio $1-1,5 \mathrm{~mm}$, ápice ca. $1 \mathrm{~mm}$, pistilódio ca. $0,3 \mathrm{~mm}$, estames ca. 2-2,5 mm; brácteas laterais $1,2-2$ $\mathrm{mm}$ de compr.

Ocorre no Brasil sudeste e sul, até a Bolívia, em floresta estacional semi-decidual, em altitudes entre 200 a $700 \mathrm{~m}$.

Material examinado: BRASIL. s.l., s.d., Burchell 2712 (K). ESPÍRITO SANTO: Dores do Rio Preto, Fazenda Cachoeira Alegre, 13.IX.2000, E.A.Costa 73 (RB). MINAS GERAIS: Caldas, 18.IX.1867, A.F.Regnell 233 (P). RIO DE JANEIRO: Nova Friburgo, Estrada entre Muri e Nova Friburgo, 13.II.2000, B.E.Diaz 216 (GUA, RB). SÃO PAULO: Apiaí, PETAR, Núcleo Caboclos, Trilha da Pescaria e do Desmoronado, 5.XII.2009, Miashike 1 (SPSF); Campinas, Sub distrito de Sousas, 18.X.1996, K.Santos 109 (RB); Itararé, "Canyon" do Rio Itararé, próximo à estrada para Sengés, 4.VI.1994, 
V.C.Souza 6167 (SP); Pariquera-Açu, Rodovia para Cananéia, beira de estrada, Fazenda Esteiro do Morro, 1.I.1995, L.C.Bernacci 1133 (SP); Paulínia, 26.III.1992, S.Pompéia (SP); Rio Claro, Fazenda São José, 2003, A.P.Teixeira (SP).

Ficus ernanii assemelha-se a $F$. adhatodifolia, mas se diferencia pelas estípulas (face externa híspida $v s$. glabra), pela face abaxial da lâmina (híspida e escabra vs. glabra e lisa), compr. do pecíolo $(2-4$ vs. $4-6 \mathrm{~cm})$ e indumento do receptáculo (híspido vs. glabro). Ficus ernanii foi recentemente publicada e tem como principal característica o tipo de indumento, entretanto ainda existe necessidade de análise anatômica para reconhecer a ambrangência desse táxon.

4. Ficus insipida Willd., Sp. Pl., ed. 4 [Willdenow] 4(2): 1143. 1806, nom. et typ. cons. recomendado pelo Comitê de Nomenclatura para Plantas Vasculares, W. L. Applequist, Taxon 62 (6): 1325 (2013). - Tipo conservado: Colômbia. Valle: Río Calima, región del Chocó, entre La Trojila y Guadualito, 11 Mar 1944, J. Cuatrecasas 16851 (COL!; isótipo: F!). Holótipo: Venezuela. Caracas, s.d., Bredemeyer 32 (B!).

Fig. 1d

Ficus helminthagoga Dugand, Caldasia 2: 440. 1944 EFicus anthelmintica Mart., Reise, iii. 1128. 1831, non Raeusch. 1797 nec L.C.Richard ex DC. $1816 \equiv$ Pharmacosycea anthelmintica (Mart.) Miq., London J. Bot. 7: 66. 1848. Neótipo (hic designatus): Brasil, Amazonas, Manaus, Catalão, Paraná do Xiborena, 10.I.2007, O.A.Santos 177 (INPA!).

Árvores com raízes tabulares na base, caule 10-30(40) m alt., casca macia, acinzentada. Ramo terminal com estípula verde, $5-11 \mathrm{~cm}$ compr., ca. $7 \mathrm{~mm}$ largura, caduco; face adaxial lisa, subglabrada; face abaxial glabra. Folha com lâmina 16-30 × 7-12,5 cm, elíptica, ápice agudo, base aguda, cartácea; face abaxial verdeamarelado escuro, lisa ou escabra, híspida ou pubérula; face adaxial verde-amarelado claro com pontuações claras, lisa ou escabra, esparsamente pubérulo; venação amarelada, nervura principal divergindo em nervuras secundárias a cada 9-12 $\mathrm{mm}$ por lado; nervuras secundárias medianas verde-esbranquiçadas, 4,5-6 cm compr., 19-21(27) pares, arqueadas, curvadas no ápice, unindo a nervura secundária supradjacente em ângulo reto, não formando nervura intramarginal, 75-80 $\mathrm{de}$ divergência da principal; pecíolo 2,5-4,5 cm compr., 2-3 mm larg., canaliculado, glabro, epiderme nãodescamante. Sicônios solitários; hipobráctea ca. 1,5 mm de compr., minuta e esparsamente pubérula, persistente ou caduca; pedúnculo 5-10 × 2-4 $\mathrm{mm}$, base alargada, pubérulo, tricomas alvos ou ferrugíneos; epibrácteas ca. $1 \mathrm{~mm}$, ápice agudo, face adaxial esparsamente pubérulo, abaxial glabra, persistentes a caducas; receptáculo verde, 1,2-2,1 cm de diâm. (tamanho natural 2-3,2 cm), esferoide, ápice subapiculado, face externa pubérula (tricomas alvos), face interna glabra; parede do receptáculo ca. $4 \mathrm{~mm}$ de larg; brácteas laterais ausentes; máculas verdes a amarelo-pálidas; ostíolo 1,5 mm de diâm. externamente; orobrácteas superiores ca. $1 \mathrm{~mm}$ de compr., caducas. Flores com tépalas rosadas a alvas, 2-3 cm de compr., ca. 0,4 $\mathrm{mm}$ de larg., esparsamente pubérula; flor longo-estiletada ca. $3 \mathrm{~mm}$ de alt., estigma ca. 0,5 mm cada lado; flor curto-estiletada ca. $2 \mathrm{~mm}$, estigma ca. 0,2 mm; flores estaminadas ca. 3-7 mm de alt., perigônio ca. $1 \mathrm{~mm}$, ápice ca. $1 \mathrm{~mm}$, pistilódio ca. $0,1 \mathrm{~mm}$ de alt., estames ca. 1,5 mm; brácteas laterais 2-3 $\times 0,4-0,5 \mathrm{~mm}$. Infrutescência vermelha a vinácea.

Ocorre na América Central de Guatemala ao Panamá, e na América do Sul, até a região amazônica, em florestas úmidas, em altitudes entre 100 a $600 \mathrm{~m}$, e mais raramente até $1.400 \mathrm{~m}$.

Material examinado: BRASIL. ACRE: Assis Brasil, Basin of Rio Purus, upper Rio Acre, 23.III.1998, D.C. Daly 9745 (UFACPZ); Mâncio Lima, Bacia do Alto Juruá, Rio Moa, entre Igarapé São Pedro e Rio Azul, 4.V.1996, M.Silveira 1199 (INPA, UFACPZ); Marechal Thaumaturgo, Rio Juruá, 7.XII.2000, D.C.Daly 10461 (UFACPZ); Rio Branco, BR-364 - R. Bujari, 1989, R.S.Saraiva 19 (INPA, UFACPZ); Estrada Sena Madureira, 6.X.1983, C.D.Mota 97 (INPA, UFACPZ); UFAC, 9.XI.2011, L.C.Pederneiras 745 (SP); Senador Guiomard, Fazenda Experimental Catuaba, 18.IV.2010, H.Medeiros 423 (RB, SP, UFACPZ); Tarauacá, Seringal Mucuripe, colocação Remanso, 11.VI.1995, C. Figueiredo 804 (UFACPZ); Bacia do Rio Juruá, 19.IX.1994, M.Silveira 841 (INPA, SP, UFACPZ); Basin of Rio Juruá, Rio Tarauacá, 24.XI.1995, D.C.Daly 8740 (UFACPZ); Seringal Boa Água, J.M.Pires 13790 (IAN); Basin of Rio Purus, near mouth of Rio Macauhan, 27.VIII.1933, B.A.Krukoff 5692 (F, GH, K); Basin of Rio Juruá, Rio Tarauacá, D.C.Daly 8558 (UFACPZ); Rio Acre, IV.1911, E.Ule 9309 (K). AMAZONAS: Aranapu, near Tefé, 3.VII.1994, W.D.Hamilton 304 (K); Ilha Aramaçá, almost opposite Tabatinga, 24.VII.1973, G.T.Prance 16777 (INPA, $\mathrm{K})$; Reserva de Desenvolvimento Sustentável de Mamirauá, 1999, M.A.D.Souza 601 (INPA); riverside of Rio Amazonas, 8.VIII.1987, S.Tsugaru 791 (GH); Paciência, Solimões, 23.I.1924, J.G.Kuhlmann 1202 (INPA, RB); Paraná do Xiborena, 1969, L.F.Coêlho 2195 (INPA); Benjamim Constant, Hotel Cabanas, 6.XI.2011, 
L.C.Pederneiras 740 (SP); Borba, margem do Rio Madeira, 28.IV.1937, A.Ducke (RB); Fonte Boa, Rio Solimoes and Rio Javari, 1973, E.Lleras 17478 (F, INPA,K, US); Guajará, Rio Campina, 16.X.2011, M.G.Bovine 3282 (SP); Ipixuna, Margem do Rio Crós, 15.II.2009, A.Quinet 1586 (RB); Limoeiro, Estação Ecológica do Juamí-Japurá, 1986, C.A.C.CidFerreira 7231 (F, INPA, K, US); Manaus, Catalão, Parana do Xiborena, 2007, O.A.Santos 177 (INPA); Ilha da Marchantaria, 1976, O.P.Monteiro 1203 (INPA); Island Paciência, 12.VIII.1936, B.A.Krukoff 8039 (F, GH, K, NY); Manicoré, margem esquerda do Rio Madeira, Comunidade Agua Azul, 7.IV.2007, A.R.Junqueira 689 (EAFM); São Paulo de Olivença, near Palmeras, 26.X.1936, B.A.Krukoff 8563 (F, GH, K, P); Solimões/Amazon, s.d., Spruce 1641 (K); Tefé, Lago Mamirauá, 2002, M.G.Guterres 46 (INPA); Uarini, São João, 2001, S.F.R.Rocha 49 (INPA); Presidente Figueiredo, Rebio Uatumã, 5.II.2008, F.A.Carvalho 108 (INPA); Região do Rio Jari, Estrada entre Bandeiras e Pilão, Km 39, 6.VI.1969, N.T.Silva 2126 (IAN, RB). PARÁ: Tucumã, Fazenda Krimet, 1982, J.E.L.S.Ribeiro 93 (INPA); beira do Rio Ituqui, São Sebastião, 20.VI.1947, G.A.Black 893 (IAN); Novo Repartimento, BR-422, beira da estrada, 7.X.2012, G.Pelissari 238 (SP); Tucuruí, Lago do Cagancho, 13.X.1983, J.Revilla 8657 (INPA); Rio Itacaiunas, afl. do Tocantins, Serra Buritirama, IX.1970, J.M.Pires 12966 (IAN). RONDÔNIA: Ouro Preto do Oeste, BR364, Reserva de Pesquisa Ecológica do INPA, 1988, J.Lima 1058 (INPA).

Foi feita consulta à coleção de Munique e também consulta on line no herbário de U e BR, mas não foi encontrado o tipo de Ficus anthelminthica, provavelmente destruído durante a Segunda Guerra Mundial. Com isso, designa-se aqui o neótipo O.A.Santos 177 (INPA) por estar na localidade típica (Manaus) e por possuir os caracteres morfológicos descritos pelo protólogo, como folha de lâmina elíptica, base obtusa, ápice agudo, nervura baselaminar com glândulas, nervuras paralelas e receptáculo solitário. Esse neótipo também concorda com o desenho de Miquel (1853: t. 25, II), provavelmente o espécime de Martius, com ca. 21 pares de nervuras secundárias. Nós poderíamos propor a própria prancha de Miquel (t. 25) como neótipo, mas preferimos um espécime de herbário por permitir observar com maior acurácia a textura e o indumento de suas partes.

Ficus insipida é caracterizada por folhas com face abaxial pubérula a glabra, porém em raros casos são encontradas notavelmente híspidas, o que são chamadas de F. insipida subsp. scabra C.C.Berg.
5. Ficus maxima Mill., nom. cons., Gard. Dict., ed. 8. Ficus no. 6 (1768). Tipo cons.: Brasil, Amazonas, Humaitá, near Três Casas, 2.X.1934, B.A.Krukoff 6413 (NY!, isótipo: A, BM!, F!, G!, GH!, GUA, K!, MO, RB!, U, US!). Fig. 2a Ficus daphniphylla Miq., Ann. Mus. Bot. Lugduno-Batavi iii. 300 (1867). EPharmacosycea laurifolia Miq., London J. Bot. 7: 71 (1848). Tipo: Brasil, Amazonas, Rio Japurá, XII/1819, Martius 9 (M!, isótipo: U, B!).

Pharmacosycea grandaeva Mart. ex Miq. London J. Bot. 7: 70 (1848). Tipo: Brasil, Amazonas, próximo ao Rio Amazonas, XI/1819, Martius 7 (M!, isótipo: U).

Árvores 5-30 m de alt. Ramo terminal com estípula 1,5-2,5 cm compr., 3-10 mm de larg.; face abaxial lisa, hirsuta, pubérulo ou glabra (tricomas alvos); face abaxial glabra a esparsamente pubérula. Folha com lâmina 8-21(30) × 4-10(12) cm, elíptica, ovada ou obovada, ápice acuminado-cuspidado, agudo, base aguda, margem plana, cartácea; face abaxial escabra, pubérula; face adaxial lisa a minutamente verrucosa, pubérula ou glabra; nervura principal alcançando o ápice, divergindo em nervuras secundárias a cada 10-27 mm por lado; nervuras secundárias medianas 4,5-9 cm compr., 8-16(18) pares, arqueadas, curvadas no ápice, unindo a nervura secundária supradjacente em ângulo reto, não formando nervura intramarginal, $70-80^{\circ}$ de divergência da principal; pecíolo 0,8-4 cm compr., 2-4 mm larg., circular, sem sulco, estriado, híspido a pubérulo, epiderme descamante. Sicônios solitários; hipobráctea ca. $1 \mathrm{~mm}$ de compr., deltoide, minuta e esparsamente pubérula, caduca; pedúnculo 4-20 × 1-2 mm, não-descamante, hirsuto a pubérulo (tricomas alvos), com lenticelas; epibrácteas $1-1,5 \mathrm{~mm}$, ápice agudo, face adaxial esparsamente hirsuto, abaxial glabra; receptáculo 1,3-2,5 cm de diâm. (tamanho natural 2-3,7 cm), esferoide, ápice arredondado, face externa híspida a pubérula (tricomas alvos), escabra, face interna pubérula; parede 2-3 $\mathrm{mm}$ de larg.; brácteas laterais ausentes; máculas verde-claras; ostíolo $1 \mathrm{~mm}$ de diâm. externamente; orobrácteas superiores ca. $1 \mathrm{~mm}$ de compr., caducas. Flores com tépalas rosadas, 2-3 × 0,4-1 mm, glabras; flor longo-estiletada ca. $5 \mathrm{~mm}$ de alt., estigma ca. 1 mm cada lado; flor curto-estiletada ca. $3 \mathrm{~mm}$, estigma ca. 0,2 mm; flores estaminadas 3-3,5 $\mathrm{mm}$ de alt., perigônio ca. $1 \mathrm{~mm}$, ápice ca. $2 \mathrm{~mm}$, pistilódio ca. $1 \mathrm{~mm}$ de alt., base alargada, estames 
2,5-3 mm; brácteas laterais $2-3,5 \times 0,1-0,4 \mathrm{~mm}$. Infrutescência amarelada.

Ocorre do norte do México (Sonora) e Antilhas até a região amazônica brasileira e boliviana, em florestas úmidas, em altitudes até $1.800 \mathrm{~m}$.

Distribuição e habitat: BRASIL. ACRE: Bujarí, Riozinho Andirá, Sul da BR364, 25.II.2009, P.AcevedoRodriguez 13053 (RB); Cruzeiro do Sul, Vila Porto Walter, Rio Juruá, 3 km atrás da vila, 26.X.1991, C.A.Cid-Ferreira 10390 (INPA, UFACPZ); Mâncio Lima, Rio Moa, Bacia do Alto Juruá, 31.V.1994, M.Silveira 791 (INPA, UFACPZ); Marechal Thaumaturgo, Rio Juruá, Reserva Extrativista do Alto Juruá, 3.IV.1993, D.C.Daly 7740 (INPA, UFACPZ); Rio Branco, Parque Zoobotânico, bloco 1, 10.VIII.1992, G.Claros 173 (INPA, UFACPZ); Igarapé São Francisco do Espalha, 22.IX.2007, C.S.Pessôa 446 (RB); Senador Guiomard, Fazenda Experimental Catuaba, 18.IV.2010, H.Medeiros 403 (SP). AMAPÁ: Laranjal do Jari, 4.VI.2010, E.S.Leal 249 (RB, SP); Munguba, Serra do Navio, 9.IX.2012, G.Pelissari 213 (SP). AMAZONAS: Rio Solimões, Careiro, Reserva de Desenvolvimento Sustentável de Mamirauá, 2000, M.A.D. deSouza 1175 (INPA); Barcelos, 2.VIII.1991, G.Martinelli 14654 (RB, SP); Borba, Barra de São Manuel, 23.V.1977, N.A.Rosa 1934 (INPA, RB, US); Humaitá, Right bank of Rio Madeira, 15.V.1985, A.J.Henderson 474 (INPA, K, US); 3.XII.1966, G.T.Prance 3575 (COL, INPA, F,K, US); near Tres Casas, 14.X.1934, B.A.Krukoff 6094 (F, GH, IAN, K, US); Três Casas, 19.IX.1962, A.P.Duarte 7191 (INPA, F, RB, US); Manaus, Entrada da UFAM, Rodrigo Otávio, 16.I.2007, O.A.Santos 170 (INPA); Reserva Ducke, 1994, C.A.Sothers 205 (INPA); IFAM, 19.IX.2012, G.Pelissari 215, 217 (SP); Reserva Ducke, 22.IX.2012, G.Pelissari 218 (SP); na entrada da cidade, 25.IX.2012, G.Pelissari 231 (SP); 6.IV.1971, P.J.Maas 263 (F); IFAM, 27.X.2011, L.C.Pederneiras 701, 703 (EAFM, SP); INPA, 28.X.2011, L.C.Pederneiras 705 (EAFM, SP); INPA/VS, 15.IV.2000, V.F.Kinupp 1212 (INPA); Flores, 12.III.1924, J.G.Kuhlmann 1611 (RB); Reserva Florestal Ducke, 24.IV.1996, J.E.L.S.Ribeiro 1819 (INPA, K); Estrada da BR-17, 6.XII.1960, W.A.Rodrigues 1988 (INPA); Igarapé do Buião, 2.X.1962, W.A.Rodrigues 4666 (INPA, GH); Km 9 da BR-17, 25.VII.1955, J.Chagas (INPA); Rosa de Maio - Colônia Santo Antônio, 25.XI.1975, O.P.Monteiro (INPA); Estrada da Reserva Florestal Ducke, 19.III.1958, Pessoal do C.P.F. (INPA, GH); Namorado Novo, entre Rio Curuquetê e Rio Madeira a Abunã, 30.VI.1971, G.T.Prance 14695 (F, GH, INPA, US); Novo Airão, Parna Jaú, Base Carabinani, 29.XI.2006, O.A.Santos 176 (INPA, MG); Paraná do Cadajás Mirim, 15.IV.1976, F.Mello 57960 (MG); 15.IV.1976, L.Coêlho 2196 (INPA); Projeto RADAM/BRASIL, 15.IV.1976, L.F.Coêlho 2199 (INPA); Presidente Figueiredo, Rebio Uatumã, 20.III.2008, J.F.Stancok 172 (INPA); Rebio Uatumã, 7.VII.2007, S.Sakagawa 385 (INPA); Balbina, 29.IV.2012, D.Cardoso 2900 (INPA); Rebio Uatumã, Balbina, 12.VIII.2008, M.F.F.Melo 514 (INPA); São
Gabriel da Cachoeira, 30.XI.1978, C.Damião 2930 (COL, INPA); Tefé, Lago Mamirauá/Setor Mamirauá, 1.VI.2002, M.G.Guterres 48(INPA); 15.X.1982, C.A.CidFerreira 3259 (INPA, K, MG, NY, RB, US); Rio Negro, Paraná Tauatú, acima de Manaus, 25.VI.1979, L.A.Maia 6 (INPA); Rio Xeriuini, 6.VII.1995, A.A.Oliveira 2686 (INPA); Alto Rio Negro, Ilha Novo retiro, 17.IV.1967, W.A.Rodrigues 8387 (INPA). MATO GROSSO: Km 330 da Rod. BR-174, 9.VI.1979, M.G.Silva 4838 (MG); Cáceres, 30.X.1985, C.A.Cid Ferreira 6574 (F, INPA, $\mathrm{K}, \mathrm{MG}, \mathrm{UFACPZ}$, US); Dardalenos, Clareira Jurema, 24.VI.1974, M.R.Cordeiro 202 (IAN); Pontes e Lacerda, Cataco, 9.XI.1996, G.Hatschbach 65455 (SP). PARÁ: Rios Pacaja and Muirapiranga. Banks of Rio Pacaja, 15.X.1965, G.T. Prance 1631 (IAN, K, MO, P, US); Belém, Bosque Rodrigues Alves, 11.X.2012, G.Pelissari 243 (SP); Embrapa, 18.X.2011, L.C.Pederneiras 679 (IAN, SP); Bosque Rodrigues Alves, M.R.Cordeiro 4351 (IAN); Conceição do Araguaia, 14.II.1980, T.Plowman 8824 (F, INPA, MG, US); Juruti, Ramal do Capiranga-solo argiloso amarelo, 8.XI.2007, M.B.Ramos 460 (INPA); Santarem, Taperinha, Paraná do Aiaiá e Paraná do Ituqui, 10.VII.1927, A. Ginzberger 636 (F); Vigia, Santo Antonio, 6.IV.1961, W.A.Egler 1604 (MG); Ilha de Marajó, Rio Anajás, acima de Anajás, Cuanta, 2.XI.1957, A.S.Tavares 322 (INPA). RONDÔNIA: Calama, Rio Madeira, IV.1980, M.Goulding 156 (MG); Rio Machado, curso inferior, II.1981, M.Goulding 1521 (MG). RORAIMA: Ilha de Maracá, 18.I.1988, W.Milliken 795 (K, MIRR).

Ficus maxima possui uma variação de tricomas (em ramos, folhas e sicônios) e forma da folha (ápice obtuso a acuminado) que causou confusão ao longo da história, levando a proposição de diversos epítetos. Analisando grande quantidade de materiais de herbários, observou-se que tais caracteres possuem continuidade entre seus estados (multiestados) e nunca uma divergência clara que possibilita a definição de diversos táxons. Ficus maxima é semelhante a Ficus ulei, porém a primeira é pedunculada (vs. séssil).

6. Ficus maximoides C.C.Berg, Blumea 52(3): 579-580, fig. 7. 2007. Tipo: Peru, Amazonas, Condorcanqui, Distrito El Cenepa, Mamayaque, 20.II.1997, Rodríguez et al. 1574 (MO, isótipo: BG!, F!, NY!).

Fig. $2 b$

Árvores 5-25 m alt. Ramo terminal com estípula 3-6 cm compr., ca. $4 \mathrm{~mm}$ de larg.; ambas as faces glabras. Folha com lâmina $13-24 \times 2,5-5,5$ $\mathrm{cm}$, estreitamente-elíptica ou lanceolada, ápice acuminado, base aguda, cartácea; face abaxial minutamente verrucosa, glabra; face adaxial minutamente verrucosa, glabra; nervura principal divergindo em nervuras secundárias a cada $8-13$ $\mathrm{mm}$ por lado; nervuras secundárias medianas $3,5-4,5$ cm compr., 16-22 pares, arqueada, unindo a nervura 

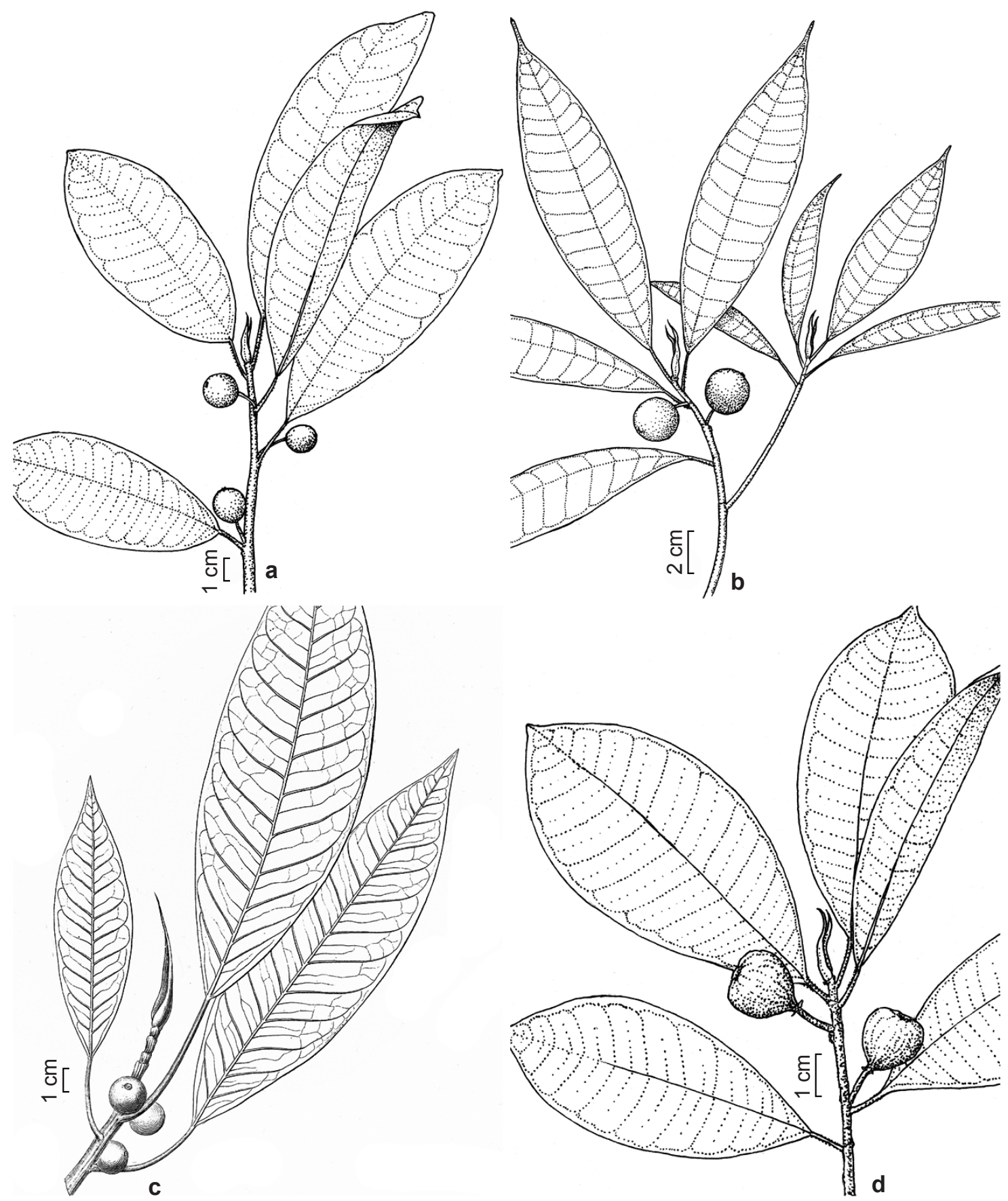

Figura 2 - Ramo com folhas, sicônios e estípulas - a. Ficus maxima; b. Ficus maximoides; c. Ficus obtusiuscula (Miquel 1853); d. Ficus pulchella.

Figure 2 - Twig with leave, syconia and stipules - a. Ficus maxima; b. Ficus maximoides; c. Ficus obtusiuscula (Miquel 1853); d. Ficus pulchella. 
secundária superadjacente em ângulo reto, 80-90 de divergência da principal; pecíolo 1,5-4 cm compr., 2-3 mm larg., canaliculado, estriado, epiderme descamante, híspida a glabrescente. Sicônios solitários; hipobráctea ca. $2 \mathrm{~mm}$ de compr., glabra, caduca; pedúnculo 5-7 × 1,5 mm, não-descamante, pubérulo; epibrácteas ca. $3 \mathrm{~mm}$, deltoide, ápice agudo a arredondado, faces externa pubérula a glabra, interna glabra; receptáculo verde-amarelado, 1,3-1,6 cm de diâm. (ao natural 2-4 cm), globoso, ápice plano a levemente aprofundado, face externa e interna pubérula; parede com 4-5 mm de larg.; ostíolo $1 \mathrm{~mm}$ de diâm. externamente; orobrácteas superiores ca. 1,5 mm de compr., persistentes. Flores com tépalas rosadas a alvas, ca. $2 \times 1 \mathrm{~mm}$, pubérulas; flor longo-estiletada ca. $4 \mathrm{~mm}$ de alt., estigma ca. $1 \mathrm{~mm}$ cada lado; flor curto-estiletada, 4-5 mm, estigma $0,1-0,3 \mathrm{~mm}$; flores estaminadas $5-7 \mathrm{~mm}$, perigônio ca. $2 \mathrm{~mm}$, pistilódio ca. $0,5 \mathrm{~mm}$, estames 1,5-2 mm; brácteas laterais 3-6 mm. Infrutescência amarelo-avermelhado.

Ocorre nos montes e planícies da Amazônia peruana, alcançando o Acre, no Brasil, em florestas úmidas de terra firme, em altitudes entre 200 a $1.300(1.800) \mathrm{m}$.

Material examinado: BRASIL. ACRE: Jordão, Tarauaca, Seringal Fortaleza, 3.X.1993, J.F.Ramos 2692 (INPA).

Ficus maximoides foi recentemente proposta (Berg 2007) sendo próxima a F. ulei, espécie simpátrica (região amazônica peruana). A primeira diferencia-se da segunda principalmente pelo compr. da estípula (3-6 vs. 1,3-1,6 cm), largura e forma da lâmina (2,5-5,5 vs. 6,5-9 cm; estreitamente-elíptica ou lanceolada $v s$. obovada a elíptica), espaçamento entre nervuras secundárias (8-13 vs. 16-23 mm), número de nervuras secundárias (16-22 vs. 9-12) e pedúnculo (5-7 vs. séssil-1,5 mm).

7. Ficus obtusiuscula (Miq.) Miq., Ann. Mus. Bot. Lugduno-Batavi 3: 300. 1867 E Pharmacosycea obtusiuscula Miq., London J. Bot. 7: 69. 1848. Tipo: Brasil, Bahia, Rio Itabira, XII.1818, Martius sn (M18825!, isotipo: U4662).

Fig. 2c Pharmacosycea perforata Miq. var. angustifolia Miq., London J. Bot. 7: 69. 1848. Lectótipo (hic designatus): Brasil, Minas Gerais, São Romão, I.1840, G.Gardner 5181 (P00756581!, isolectótipo: BM!, E!, F!, G!, GH!, K!, NY!, P00756582!, US!). Ficus mima Standl., Publ. Field Mus. Nat. Hist., Bot. Ser. 17(2): 173. 1937. Tipo: Brasil, Mato Grosso, nascente do Rio Jatuarana, região do Rio Machado, XII.1931, B.A.Krukoff 1640 (F!, isótipo: BM!, G!, K!, MO, NY!, P!, U).
Árvore com caule 10-15 m alt., 40-55 cm larg., casca macia. Ramo terminal com estípula verde, 3-5 cm compr., 3-5 mm larg., ápice acuminado, abraçando $1 / 2$ do caule, margem inteira a ondulada, caducos; face adaxial lisa, subglabrata; face abaxial glabra. Folha com lâmina 9-12 × 3,5-5 cm, elíptica, ápice acuminado, base cuneada, cartácea; face abaxial lisa, pubérula nas proximidades da nervura principal; face adaxial lisa, subglabrata; nervura principal divergindo em nervuras secundárias a cada $5-9 \mathrm{~mm}$ por lado; nervuras secundárias medianas 2,5-3,5 cm compr., 12-14 pares, arqueadas, curvadas no ápice, unindo a nervura secundária superadjacente em ângulo reto, não formando nervura intramarginal, 60-70 de divergência da principal; pecíolo 1,5-3 cm compr., 1-1,5 mm larg., canaliculado, pubérulo ou híspido, epiderme não-descamante. Sicônios geminados; hipobráctea ca. $2 \mathrm{~mm}$ de compr., minutamente pubérula, caduca; pedúnculo 2-3× $1 \mathrm{~mm}$, pubérulo; epibrácteas 1-2 mm, ápice agudo, ambas as faces glabras, persistentes; receptáculo verde, 5-7 $\mathrm{mm}$ de diâm. (tamanho natural ca. 1 $\mathrm{cm}$ ), esferoide, ápice arredondado, face externa minutamente pubérula (tricomas ferrugíneos ou alvos), face interna pubérula; parede do receptáculo ca. 0,5 mm de larg.; brácteas laterais ausentes; máculas claras; ostíolo parte externa 1,5 $\mathrm{mm}$ de diâm., parte mediana $1 \mathrm{~mm}$ de diâm., parte interna 1,5 mm de diâm.; orobrácteas superiores vináceas, 0,3-0,5 mm de compr., ápice arredondado a agudo, caducas. Flores com tépalas alvas a rosadas, ca. $2 \times 1 \mathrm{~mm}$, esparsamente pubérulas; flor longoestiletada 1,2-1,5 mm de alt., estigma ca. 0,2 $\mathrm{mm}$ cada lado; flor curto-estiletada 1,5-3 mm, estigma ca. $0,1 \mathrm{~mm}$; flores estaminadas ca. $2 \mathrm{~mm}$, pistilódio ca. $0,3 \mathrm{~mm}$, estames $1,5-2 \mathrm{~mm}$; brácteas laterais 1-2,5 mm. Infrutescência vinácea.

Ocorre do Brasil ao Paraguai e Misiones na Argentina, em florestas úmidas, geralmente em mata ripárias, em altitudes até $1.000 \mathrm{~m}$.

Material examinada: BRASIL. F.Alemão 1433 (P); 1863-1866, J.E.B.Warming 1898 (P); Burchell 7744 (K). AMAZONAS: Borba, BR-230 Estrada Transamazônica, 1985, A.J.Henderson 404 (INPA, MG); Manicoré, BR230, Rodovia Transamazônica, Km 302, 24.IV.1985, C.A.Cid-Ferreira 5774 (RB, INPA, US, K). BAHIA: VIII.1980, G. Pedra do Cavalo 542 (K, RB); Bom Jesus da Lapa, ao lado do Rio São Francisco, 27.VII.2000, B.E.Diaz 371 (RB); Conde, margem do Rio do Bu, 12.IX.1996, M.C.Ferreira 1068 (RB); Itaite, border of Paraguassu River, 17.X.1942, R.L.Fróes 12649 (GH); Morro do Chapéu, Ventura, Beira do rio, 4.III.1997, F.França 6011 (SP, ALCB); entre Botirama e Paratinga, 
28.I.1970, J.P.P.Carauta 1021 (GUA). BRASÍLIA: Bacia do Rio São Bartolomeu, 9.VIII.1979, E.P.Heringer 1940 (K); Riacho Vicente Pires, 12.VII.1966, H.S.Irwin 18167 (RB, IAN); Fercal, região do Calcário, margem do córrego, 10.XII.1964, R.P.Belém 2 (IAN, GH); 8. VIII.2007, B.M.T.Walter 1407 (RB); Lagoa Encantada, 28.I.1980, E.P.Heringer 3450 (K); Córrego Vicente Pires, setor industrial, 12.VII.1966, D.R.Hunt 6617 (K); Riberão da Contagem, 14.XII.1965, H.S.Irwin 11297 (GH); Côrrego Landim, 17.III.1966, H.S.Irwin 14043 (F, US, GH); Área do Zoobotânico, 17.XI.1967, A.P.Duarte (GUA). ESPÍRITO SANTO: Bom Jesus do Norte, 7.VI.1982, J.P.P.Carauta 4277 (GUA); Dores do Rio Preto, 12.X.2000, E.A.Costa 85 (RB); Mimoso do Sul, 16.VII.2008, R.A.X.Borges 909 (RB). GOIÁS: Chapada dos Veadeiros, 8.IX.1994, M.L.Fonseca 111 (RB, US); Alto Horizonte, Rio dos Bois, 20.VIII.1996, S.S.Silva 15 (SP, IBGE, GUA); Barro Alto, Estrada para a Barra dos rios Maranhão e Almas, 8.II.1996, B.M.T.Walter 3114 (SP, GUA); Caldas Novas, próximo à foz do Ribeirão Pirapitinga, 11.II.1993, S.P.Cordovil 218 (SP, GUA); Cavalcante, margem esquerda do Rio Macacão, 21.II.2001, G.Pereira-Silva 4752 (RB, SP); 4,5 km da Vila Veneno, 25.I.2001, B.M.T.Walter 4796 (SP, RB); Corumbá de Goiás, em direção ao Rio Corumbá, 23.XI.2011, D.P.Saraiva 288 (SP, RB); Corumbaiba, margem esquerda do Rio Corumbá, 19.VII.1993, H.G.P.Santos 200 (SP); Ipameri, Rio Corumbá, a montante da Ponte de São Bento, 25.IV.1997, S.P.C.Silva 601 (SP, GUA); Reservatório da UHE Corumbá, 18.VII.1997, S.P.C.Silva 667 (SP, GUA); Iporá, Bacia do Rio Caiapó, Rio Caiapó, 15.X.2007, S.Sousa Silva 368 (SP); Luziânia, 9.XII.2002, J.M.Rezende 671 (RB, SP); Niquelandia, 3.VIII.1992, T.S.Filgueiras 2391 (US); margem direita do Rio Maranhão/Tocantins, 25.X.1995, B.M.T.Walter 2873 (SP, GUA); Piranhas, drainage of the Upper Rio Araguaia, 22.VI.1966, H.S.Irwin 17585 (F, US, GH, K); Rio Piranhas, região do Araguatins, 27.IV.1961, E.Oliveira 1583 (IAN, RB); Silvania, confluência do Rio Antas com o Rio Corumbá, 11.III.2003, G.Pereira-Silva 7363 (SP); Uruacu, 26.VI.1996, B.M.T.Walter 3347 (SP, GUA); Vianópolis, Rod. GO-010, 13.XII.2004, P.G.Delprete 9155 (RB). MARANHÃO: Benedito Leite, margem esquerda do Rio Parnaíba, 26.I.2005, A.M.Miranda 4851 (SP); Fortuna, Buriti-Bravo, 22.II.1983, G.E.Schatz 737 (US, MG, K); Loreto, 22.II.1970, G.Eiten 10748 (SP, US); Viana, 1957, O.Carvalho 1 (RB); Parnaíba, 1877, Jobert 1148 (P). MATO GROSSO: margem do Rio Aripuanã, 1977, M.Gomes 496 (INPA); Km 330 da rodovia BR-174, Rio Tucunã, 11.VI.1979, M.G.Silva 4864 (RB, SP); Alta Floresta, Ilha Ariosto da Riva, 23.I.2007, D.Sasaki 1393 (INPA, K); Araputanga, 22. II.1956, N.Crud (GUA); Chapada dos Guimarães, Rio Quilombo, 13.VIII.1997, Hatschbach. 66876 (GUA); Cuiabá, s.d., M.Weddel 3092 (P); Gaúcha do Norte, beira do Rio Pacuneiro, 17.II.2000, N.M.Ivanauskas 4277 (SP); Juína, beira do Rio Vermelho, 1997, V.C.Souza
18334, 18335 (INPA, SP); Nova Xavantina, margem do Rio das Mortes, 15.IX.2010, G.P.Iduarte 25 (SP); 30. IX.1999, B.S.Marimon 443 (SP); Paranatinga, margem esquerda do Rio Jatobá, Agrochapada, 28.X.1990, M.Macedo 2981 (SP, INPA); Santa Cruz do Xingu, Parque Estadual do Xingu, Rio Fontourinha, 12.III.2011, W.Milliken 4275 (SP); Xavantina, Rio das Mortes, 26. VIII.1967, P.W.Richards 495 (P, K). MATO GROSSO DO SUL: margem do Rio Paraná, 16.X.1998, L.R.H.Bicudo 227 (SP); Bataguaçu, Porto XV, 24.I.1992, M.Madalena (SP). MINAS GERAIS: Araxá, Estrada entre Araxá e Uberaba, 14.V.2000, B.E.Diaz 1171 (RB); Astolfo Dutra, 6.IV.1998, A.Salino 4157 (GUA); Braúnas, X.1993, E.Tameirão Neto 889 (GUA, F); Buritis, Fazenda Mangues, 10.VI.1996, P.P.Monteiro 104 (SP); Cabeceira Grande, região da ponte sobre o Rio Preto, 14.II.2002, A.C.Sevilha 2111 (SP, RB); Carangola, Rio Carangola, 29.V.1988, L.S.Leoni 1 (GUA); Carmo, Ituiutaba, 18.XI.1957, A.Macedo 3408 (US); Coroací, 28.III.1976, G.Davidse 11472 (SP); Faria Lemos, Fazenda Santa Isabel, 27.X.1992, L.S.Leoni 1997 (GUA); Januária, Distrito de Fabião, 26.X.1997, J.A.Lombardi 2116 (GUA); Laranjal, 7.II.1979, P.L.Krieger 10013 (GUA); Montes Claros, 9.XI.1938, Markgraf 3133 (RB, F); VI.1948, H.Paula 55038(COL, F, GH, SP); Muraé, 13.III.1958, A.Lima 2933 (K); Nova Ponte, Floresta ciliar do Rio Araguari, 4.XII.1996, E.Tameirão Neto 2198 (GUA); 18.X.1986, Stehmann (GUA); Paracatu, 12.I.1980, J.P.P.Carauta 3361 (RB, SP, GUA); Ponte Nova, 3.VIII.1995, G.E.Valente 115 (SP); III.1997, L.V.Costa (RB); S. Terezinha, Ituiutaba, 17.XI.1951, A.Macedo 3402 (US); Santa Juliana, Pedralli (GUA); Santa Luzia, Fazenda do Cipó, 20. IX.1937, M.Barreto 9131 (SP, F); Serra do Cipó, 6. III.2009, D.C.Zappi 1807 (RB); Taguara, Ponte da Taguara, 10.X.1958, E.P. Heringer 6603 (IAN, US); Uberlândia, beira do Rio Araguari, 11.VII.1991, I.Schiavini 311 (SP); Capim Branco, 14.II.2007, P.O.Rosa 403 (SP); Rio Araquari, 20.VII.1993, E.Tameirão Neto 939 (GUA); Reservatório de Miranda, 29.IV.2003, R.Romero 6789 (SP); APP Capim Branco I, 17.II.2005, G.M.Araújo (SP); Unaí, próximo ao Ribeirão Cana Brava, 27.XI.203, B.A.S.Pereira 3471 (SP); Várzea da Palma, Fazenda Jatobá, próximo de Jiquitahi, 26. XI.1962, A.P.Duarte 7508 (RB, US); Viçosa, Duas Barras, 8.VIII.2007, P.P.Souza 189 (RB, SP); Sumidouro, divisa com Paula Cândido, 3.IX.2007, P.P Souza 200 (RB, SP); 1838, M.Claussen (G, K, P); UCAT, 24. II.1985, M.A.Lopes (GUA). PARÁ: Rio Itapacurú, 4. IV.1924, J.G.Kuhlmann 1902 (RB); Rio Cupary, afluente do Tapajós, 11.IV.1924, J.G.Kuhlmann 1976 (RB); Igarapé Capanema, 10.X.2012, G.Pelissari 241 (SP); Santa Luzia do Pará, afluente do Rio Gurupi, 4.X.2012, G.Pelissari 235 (SP); Serra dos Carajas, Rio Parauapebas, 23.VI.1982, C.R.Sperling 6308 (MG); Beira d'água do Rio Pixuna, $40 \mathrm{~km}$ acima da boca do Cupari, 24. XII.1947, G.A.Black 1944 (IAN). PARANÁ: margem direita do Rio Tocantins, 8.VII.2002, G.Pereira-Silva 
6610 (RB, SP); Guaíra, 19.VIII.1982, G.Hatschbach 45217 (US); Icaraíma, Barra do Rio Ivai, 21.I.1967, G.Hatschbach 15812 (COL, US); Icaraíma, Ilha dos Bandeirantes, Rio Paraná, 22.I.1967, G.Hatschbach 15830 (US); Santo Antonio do Caiua, 22.VI.1966, G.Hatschbach 14440 (P, US); Ilha dos Bandeirantes, 22.I.1967, G.Hatschbach 4359 (F, US, GH, K). PIAUÍ: Amarante, Estrada de barro para Paineiras, 24.XI.2005, A.M.Miranda 5324 (SP); Oeiras, 1866, Gardner 2000 (BM, NY, K, P). RIO DE JANEIRO: margem do Rio Paraíba, 24.XII.1961, A.P.Duarte 5724 (RB); Bom Jesus de Itabapoana, 8.VI.1982, J.P.P.Carauta 4308 (GUA); Campos, 8.VIII.1876, A.Glaziou 10059 (P); Carmo, Porto Novo, 4.VII.1936, M.Barreto 1389 (F); Guapimirim, Estrada para o Centro de Primatologia, 1.XI.2010, L.C.Pederneiras 619 (SP); Itaocara, à margem do Rio Paraíba do Sul, 25.VIII.1981, J.P.P.Carauta 3831 (GUA); Itatiaia, Rio Campo Belo, 1.II.2001, P.P. Souza 84 (RB); Paranagoá, VIII.1839, Gardner 2730 (BM, K, P); VIII.1839,Gardner 2731 (BM, K, US); Porciúncula, margem do Rio Carangola, 1.XI.1979, R.Ribeiro 32 (GUA); Resende, Av. Presidente Kennedy, 16.II.2011, G.Pelissari 201 (SP); Porto Real, 22.X.1981, J.P.P.Carauta 4273 (RB); Santo Antônio de Pádua, 21.VII.2005, C.A.L.Oliveira 2676 (GUA); Aperibé, 29.IV.1981, J.P.P.Carauta 3780 (RB, GUA, F, K); Silva Jardim, margens do Rio São João, 24.I.1994, D.S.Farias 113 (RB, K); Poço das Antas, 24.XI.1976, R.F.Oliveira 256(GUA); Vassouras, Aliança, 13.V.1980, J.P.P.Carauta 3500 (RB, SP, GUA, F); Ipiranga, na borda do Rio Paraíba, 29.XI.1880, A.Glaziou 12165 (K, P); Graham (K). RONDÔNIA: Rio dos Pacas Novos, 27. III.1978, W.R.Anderson 12283 (US, GH); Porto Velho, Rio Jamari, 13.VIII.1987, F.Dionizia 150 (INPA); Área do Reservatório da Usina Hidrelétrica de Samuel, 1986, C.A.Cid-Ferreira 7471 (INPA, F, US, K); Rio Jamari, Igarapé do Japlim e Lagoa de Feijoal, 13.VIII.1987, F.Dionizia 149 (F); Rio Machado, I.1981, M.Goulding 1336 (MG). SÃO PAULO: Jardinópolis, margem do Rio Pardo, 18.VII.2007, R.A.S.Pereira 148, 149 (RB, SPFR); Paulínia, Rio Jacaré-Pepira, 20.III.1991, S.Pompéia (SP); Presidente Epitácio, Reserva Estadual Lagoa São Paulo, 17.V.1995, M.Kirizawa 3131 (SP); Ribeirão Preto, margem do Rio Pardo, 21.XI.1947, M.Kuhlmann 1646 (SP, GUA); Serrana, Usina da Pedra, 15.IX.2005, R.A.S.Pereira 118 (SP, SPFR); Teodoro Sampaio, margem do Rio Paraná, 29.XI.1992, E.L.M.Catharino 1927 (SP); Rio Tiete, VII.1826, L.Riedel 383 (US). TOCANTINS: Lagoa da Confusão, Ilha do Bananal, Parque Nacional do Araguaia, 25.III.1999, R.C.Mendonça 4019 (GUA); Palmeirópolis, margem esquerda do Rio Tocantins, 11.VII.2007, G.Pereira-Silva 11945 (RB); Paraná, margem direita do Rio Tocantins, 27.IX.2007, G.Pereira-Silva 12125 (RB); Tocantinópolis, 22. XI.1983, E.Mileski 390 (RB).

Para Miquel (1848) Pharmacosycea perforata var. angustifolia era diferente de Ficus perforata (sinônimo de Ficus adhatodifolia) por possuir folhas menores, receptáculo geminado nas axilas e pedúnculo menor, caracteres encontrados em Ficus obtusiuscula. Miquel citou dois materiais tipos: Gardner 5181 e Claussen sn, portanto, são síntipos e propomos Gardner 5181 como lectótipo por possuir ramo, folhas, estípula e sicônios, e estar depositado no herbário onde Miquel trabalhou (M).

8. Ficus pulchella Schott ex Spreng., Syst. Veg., (ed. 16) [Sprengel] 4 (2, Cur. Post.): 410. 1827. Tipo: Brasil, Rio de Janeiro, 1817-1821, Schott 50 (B100244630!).

Fig. 2d

Árvores 10-22 m alt. Ramo terminal com estípula verde, 1,5-2,5 cm compr., ca. $3 \mathrm{~mm}$ de larg.; ambas as faces glabras. Folha com lâmina 9-15(23) × 3-6,5(8) cm, elíptica a obovada, ápice obtuso, agudo ou acuminado, base aguda, cartácea; face abaxial verrucosa, pubérula; face adaxial minutamente verrucosa, subglabrata; nervura principal divergindo em nervuras secundárias a cada 3-8(14) mm por lado; nervuras secundárias medianas $2-4(5,5) \mathrm{cm}$ compr., 19-27 pares, retilínea ou levemente arqueada, abruptamente curvado no ápice, unindo a nervura secundária superadjacente em ângulo obtuso, 80-90 de divergência da principal; pecíolo $1-2(2,3) \mathrm{cm}$ compr., 2-3 mm larg., oval a canaliculado, estriado, epiderme descamante, glabra. Sicônios solitários; hipobráctea ca. $1 \mathrm{~mm}$ de compr., glabra, caduca; pedúnculo 4-13 × $1 \mathrm{~mm}$, não-descamante, glabro; epibrácteas verdes a bruneas, ca. $1 \mathrm{~mm}$, ápice agudo, ambas as faces glabras, caducas; receptáculo verde, 1,5-2 cm de diâm. (ao natural 2-4 cm), globoso, ápice plano a levemente aprofundado, face externa e interna pubérula; parede com 4-5 mm de larg.; máculas verde-claras a amareladas; ostíolo 1 mm de diâm. externamente; orobrácteas superiores 0,5 mm de compr., persistentes. Flores com tépalas rosadas a alvas, ca. $2 \times 1 \mathrm{~mm}$, pubérulas; flor longo-estiletada $4 \mathrm{~mm}$ de alt., estigma 1-2 mm cada lado; flor curto-estiletada, 3-6 mm; estigma 0,1-0,3 mm; flores estaminadas $3-4 \mathrm{~mm}$, perigônio ca. $2 \mathrm{~mm}$, lobos esparsamente pubérulas na borda, pistilódio ca. $0,5 \mathrm{~mm}$, estames $1,5-2 \mathrm{~mm}$; brácteas laterais 2-4 mm. Infrutescência amarelada.

Ocorre nas regiões costeiras das Guianas ao Maranhão (Brasil), da Paraíba ao Paraná, e nas planícies de terra firme beirando a floresta amazônica da Colômbia ao Mato Grosso (Brasil), em florestas úmidas em altitudes até $500 \mathrm{~m}$.

Material examinado: BRASIL. BAHIA: Ilhéus, Fazenda Retiro, 7.IX.1998, R.H.R.Sambuichi 181 (GUA). ESPÍRITO SANTO: Aracruz, 9.XII.2011, D.A.Folli 
6829 (SP); Conceição da Barra, Aracruz Celulose, 26.III.1992, O.J.Pereira 3144 (SP); Área 157 da Aracruz Celulose S.A., 22.IX.1992, O.J.Pereira 3885 (SP, GUA); Linhares, Reserva Natural da Vale, 15.IV.2006, G.S.Siqueira 220 (SP); Res. Flor. CVRD, 20.IX.1991, D.A.Folli 1417 (GUA); Reserva Florestal de Linhares, Aceiro Calimã Km 0,5, 11.V.1999, D.A.Folli 3419 (F, RB). MARANHÃO: São Luis, Reserva Florestal do Sacavem, 21.I.1992, F.H.Muniz 15 (INPA); Island of São Luis, Anil, IX.1940, R.Froes 11923 (GH, US). MATO GROSSO: Novo Mundo, Cristalino, 7.V.2007, D.Sasaki $1630(\mathrm{~K})$. MINAS GERAIS: Caratinga, Fazenda Montes Claros, 11.VII.1980, A.Nishimura 55 (GUA); Caratinga, Fazenda Montes Claros, 23.VIII.1980, A.Nishimura 84 (GUA); Estação Biológica de Caratinga, 20.X.1993, P.M.Andrade 417 (F, GUA, SP); Estação Biológica de Caratinga, 6.IV.1990, L.V.Costa (GUA 42701). PARÁ: Moju, Campo Experimental da Embrapa Amazônia Oriental no Km 30 da Rodovia PA-150, G.C.Ferreira 37 (IAN); Tucuruí, Breu Branco, 10.VI.1980, M.G.Silva 5445 (INPA). PARAÍBA: Espírito Santo, Engenho São Paulo, 25.XI.1968, Andrade-Lima 5479 (INPA, SP). PARANÁ: Antonina, 11.IX.1975, G.Hatschbach 37041 (US). RIO DE JANEIRO: Horto Florestal, margem do Rio dos Macacos, 11.XI.1994, C.Nogueira 2 (RB); Serra Carioca, vertente sul, subida final da Rua Sara Vilela, 16.IX.1987, R.Marquete 69 (RB); Floresta dos Três Rios, Jacarepaguá, 7.VII.1959, A.P.Duarte 4891 (F, K, RB, US); Fábrica Carioca, 8.XI.1927, Antenor (RB); Corcovado-Paineiras, 18.I.1879, A.Glaziou 11563 (K, P); Macaé, Lagoa Comprida, 27.IV.1982, D.S.D.Araujo 4997 (GUA); Parati, Morro das Laranjeiras, acesso pela Rio Santos, APA Cairuçu, 16.III.1993, E.A.Filho 108 (RB); Ponta Negra, Trilha para Cairuçu das Pedras, 12.IV.1994, R.Marquete 1589 (GUA, RB); Rio de Janeiro, Caminho do Encanamento, 20.VII.1976, M.S.Moraes 11 (GUA); Alto da Boa Vista, Estrada da Vista Chinesa, 29.IV.1991, C.A.L.Oliveira 397 (GUA); Mata do Horto Florestal, 23.X.1926, J.G.Kuhlmann 694 (RB, GUA); Corcovado, Caminho do Macaco, 18.I.1879, A.Glaziou 11560 (K, P); Silva Jardim, Reserva Biológica de Poço das Antas, 9.XI.1982, H.C.Lima 1836 (RB, SP). SANTA CATARINA: Itajaí, Morro da Fazenda, 25.V.1955, R.M.Klein 1392 (GUA, US); Morro da Ressacada, 24.I.1956, R.M.Klein 1807 (US). SÃO PAULO: Cananéia, Parque Estadual da Ilha do Cardoso, Estrada de entrada ao Núcleo Perequê, 3.VI.2004, L.R.Mendonça 3 (SP); Parque Estadual da Ilha do Cardoso, mata de encosta do morro de captação d'água, 26.VIII.1987, M.R.F.Melo 863 (SP); Parque Estadual da Ilha do Cardoso, 21.VI.1989, M.Kirizawa 2243 (SP); Caraguatatuba, Parque Estadual da Serra do Mar, Núcleo Caraguatatuba, Trilha do Poção, 22.VII.2004, L.R.Mendonça 7 (SP); Cubatão, Vale do Rio Moji, atrás da Ultrafértil, 21.VI.1986, S.L.Pompéia 1 (SP); Iguape, Reserva Ecológica Juréia-Itatins, Trilha para a Figueira, 14.XII.1990, M.P.Costa 31 (SP); Estação Ecológica Juréia-Itatins, Serra da Juréia,
Caminho do Imperador, 21.VII.1993, E.A.Anunciação 310 (SP); Reserva Ecológica Juréia-Itatins, Trilha para a Figueira, 7.XII.1994, I.Cordeiro 1478 (SP); Peruíbe, 11.X.2010, L.C.Pederneiras 570 (SP); Estação Ecológica Juréia-Itatins, Bairro do Guaraú, 30.X.2010, L.C.Pederneiras 589 (SP); arredores da Foz do Rio Guaraú, 9.X.1995, V.C.Souza 9337 (INPA, SP); Roseira, ca. 5-10 km da margem direita do Rio Paraíba do Sul, 16.VIII.1995, S.Romaniuc Neto 1411 (SP); Ubatuba, Picinguaba, 31.III.2005, R.A.S.Pereira 107 (SP, SPFR); Sede do IF, 5.III.2008, R.A.S. Pereira 164 (RB, SP, SPFR); Picinguaba, 5.V.1989, C.P.Garcia 392 (GUA).

Ficus pulchella foi citada por diversos autores (e.g., Miquel 1867; Dewolf 1965; Berg et al. 1986; Carauta 1989; Berg \& Villavicencio 2004; Pederneiras et al. 2012) no Brasil. Somente Miquel (1853) levantou a hipótese de que poderia ser um sinônimo de $F$. adhatodifolia, mais a primeiro possui 19-27 pares de nervuras secundárias e a segunda 14-16 pares. Esta espécie possui uma variação considerável de nervuras secundárias porque nervuras intersecundárias constantemente possuem o mesmo calibre que as secundárias.

9. Ficus ulei Rossberg, Repert. Spec. Nov. Regni Veg. 42: 60. 1937. Tipo: Brasil, Acre, Rio Juruá Mirim, VIII.1901, E.Ule 5716 (B!, isótipos: G!, K442909!, K442910!, MG!). Fig. 3a

Pequenas árvores 3-7(12) $\mathrm{m}$ de alt. Ramo terminal com estípula verde, 1,3-1,6 cm de compr., 3-5 mm de larg.; ambas as faces glabras, ou face abaxial esparsamente híspida. Folha com lâmina $12-20(26) \times 6,5-9(11) \mathrm{cm}$, obovada a elíptica, às vezes estreitamente elíptica a lanceolada, ápice cuspidado, base aguda, margem plana, cartácea; face abaxial lisa, glabra, mais raramente híspida; face adaxial lisa, glabra; nervura principal divergindo em nervuras secundárias a cada 1,6-2,3 $\mathrm{cm}$ por lado; nervuras secundárias medianas 4,5-10 cm compr., 9-12 pares, arqueadas, unindo a nervura secundária supradjacente em ângulo reto, não formando nervura intramarginal, $60-80^{\circ} \mathrm{de}$ divergência da principal; pecíolo $1-5 \mathrm{~cm}$ compr., 2-3 mm larg., canaliculado, estriado, epiderme descamante, glabra, raramente híspida. Sicônios solitários, raramente geminados; hipobráctea ca. 1 mm de compr., glabra, caduca; pedúnculo séssil ou até 1,5 mm, não-descamante, pubérulo ou híspido; epibrácteas 1-2 mm, deltoide, ápice arredondado, ambas as faces glabras; receptáculo verde, 1,2-2 $\mathrm{cm}$ de diâm., globoso, ápice arredondado, face interna e externa pubérula a híspida; parede ca. 4 $\mathrm{mm}$ de larg.; ostíolo $2 \mathrm{~mm}$ de diâm. externamente; 
orobrácteas superiores $1 \mathrm{~mm}$ de compr., caducas. Flores com tépalas rosadas, ca. $2 \times 1 \mathrm{~mm}$, glabras; flor longo-estiletada ca. $6 \mathrm{~mm}$ de alt., estigma 0,7-0,8 mm cada lado; flor curto-estiletada 4-8 $\mathrm{mm}$, estigma ca. 0,2 mm; flores estaminadas 8-9 $\mathrm{mm}$ de alt., perigônio ca. $3 \mathrm{~mm}$, ápice ca. $2 \mathrm{~mm}$, pistilódio $0,5 \mathrm{~mm}$ de alt., estames $2 \mathrm{~mm}$; brácteas laterais ca. $8 \times 1 \mathrm{~mm}$.

Ocorre na região amazônica de terra firme do sul da Colômbia, Equador, Peru e Bolívia, com raros indivíduos no Acre/Brasil, em florestas úmidas, em altitudes de 100 a $800 \mathrm{~m}$.

Material examinado: BRASIL. ACRE: Mun. Porto Acre, Reserva Florestal de Humaitá, C. Figueiredo 771 (UFACPZ); Cruzeiro do Sul, Rio Moa at Serra da Moa village, 27.IV.1971, G.T.Prance 12498 (INPA, F, US, GH, MG, P); Plácido de Castro, Km. 20, AC-40, Plácido de Castro-Rio Branco, 6.II.2000, I.S.Rivero 403 (UFACPZ); Tarauacá, Rio Tarauacá, Rio Tarauacá, 17.VIII.1994, D.C.Daly 8208 (INPA, UFACPZ); Traumaturgo, Rio Alto Juruá, Reserva Extrativista do Alto Juruá, 12.IV.1993, M.Silveira 532 (INPA, UFACPZ). AMAZONAS: Rio Auatí Paraná, próximo de Barreirinha, 15.IV.1970, Byron 285 (INPA).

Ficus ulei foi considerado um sinônimo de Ficus maxima por alguns autores como: Dewolf (1965), Berg et al. (1986), Carauta (1989) e Berg \& Villavicencio (2004), mas a primeira espécie se diferencia da segunda pelo pedúnculo (séssil-1,5 vs. 4-15 mm de compr.) e ápice da lâmina (sempre cuspidado vs. agudo, acuminado ou cuspidado).

10. Ficus vermifuga (Miq.) Miq., Ann. Mus. Lugduno-Batavum 3: 300. 1867. 三Pharmacosycea vermifuga Miq., London J. Bot. 7: 70. 1848. Tipo: Brasil, Rio de Janeiro, Rio de Janeiro, Corcovado, IX.1817, Martius s.n. ou 178 (M174116!; Isótipo: U4639).

Fig. 3b

Ficus nevesiae Carauta, Albertoa 10: 65-67. 2002. Tipo: Brasil, Rio de Janeiro, Rio de Janeiro, Morro da Babilônia, 12.XI.2000, B.Ernani Diaz 395 (R!, isótipo: GUA!, RB!, SP!)

Árvores com caule 15-20 m alt. Ramo terminal com estípula $3,5-5 \mathrm{~cm}$ compr., ca. 5 $\mathrm{mm}$ de larg.; face adaxial glabra; face abaxial glabra. Folha com lâmina 15-22 × (5,5)8-10(12) $\mathrm{cm}$, elíptica a ovada, ápice agudo, base aguda, cartácea; face abaxial verde clara, lisa, pubérula nas proximidades da nervura principal; face adaxial verde-clara, minutamente verrucosa, subglabrata; nervura principal divergindo em nervuras secundárias a cada $7-13 \mathrm{~mm}$ por lado; nervuras secundárias 3-5 cm de compr., 14-16 pares, arqueadas, curvadas no ápice, unindo a nervura secundária superadjacente em ângulo reto, não formando nervura intramarginal, $65-70^{\circ} \mathrm{de}$ divergência da principal; pecíolo 3,5-6 cm compr., 2-3 mm larg., redondo a canaliculado, glabro, epiderme não-descamante. Sicônios solitários; hipobráctea ca. $2 \mathrm{~mm}$ de compr., glabra, caduca; pedúnculo $0,8-2,5 \mathrm{~cm}$ de compr., 1,3-2 $\mathrm{mm}$ de larg., glabro; epibrácteas ca. $2 \mathrm{~mm}$, ápice agudo a arredondado, ambas as faces glabras, persistentes; receptáculo verde, 1,5-1,7 cm de diâm. (tamanho natural 2-3,8 cm), esferoide, obloide ou elipsoide, ápice crateriforme, face externa verrucosa, subglabrata, face interna pubérula; parede do receptáculo com espessura desigual, parte lateral com 1-2,5 $\mathrm{mm}$ de larg., parte apical 5-7 $\mathrm{mm}$ de larg.; máculas verde-claras quando jovens; ostíolo $2 \mathrm{~mm}$ de diâm. externamente; orobrácteas superiores 0,3-0,5 mm de compr., persistentes. Flores com tépalas rosadas, $1-2,5 \times 0,5-1 \mathrm{~mm}$, pubérulas na borda do ápice; flor longo-estiletada $4 \mathrm{~mm}$ de alt., estigma 0,7-0,9 mm cada lado; flor curto-estiletada ca. $3 \mathrm{~mm}$, estigma $1 \mathrm{~mm}$; flores estaminadas ca. $5 \mathrm{~mm}$, perigônio esparsamente pubérulos na borda, pistilódio ca. 0,3 $\mathrm{mm}$, estames 2-2,5 $\mathrm{mm}$; brácteas laterais $2-5 \mathrm{~mm}$. Infrutescência verde.

Endêmica do Brasil, na costa Atlântica entre Bahia e Rio de Janeiro, nas florestas úmidas de terras baixas, até $200 \mathrm{~m}$ de altitude.

Material examinado: BRASIL. BAHIA: Caravelas, Rio Caribe de Cima, Sítio Cornioba, C.Farney 4849 (RB); Ilheus, CEPEC, 3.III.1983, T.S.Santos 3846 (INPA); Itabuna, $8 \mathrm{~km}$ ao norte, Rodovia BR-101, 9.X.1975, T.S.Santos 3064 (RB). RIO DE JANEIRO: Recreio dos Bandeirantes, Parque Natural Municipal da Prainha, 8.VI.2004, L.J.T.Cardoso 165 (RB); Horto Florestal, 22.XII.1926, Pessoal do Horto Florestal 682 (RB); APA da Prainha, Trilha para o topo do Morro da Boa Vista, 30.IX.1996, J.M.A.Braga 3525 (RB); São Conrado, subida para o Joá, 9.VI.1959, A.P.Duarte 4815 (RB); Restinga de Jacarepagua, 25.7.1961, A.P.Duarte 5630 (RB, US); Cabo Frio, Restinga da Praia do Peró, 14.IX.1968, D.Sucre 3632 (RB); Praia do Peró, 14.IX.2002, A.Quinet 729 (RB); Praia do Peró, 14.VIII.1982, J.P.P.Carauta 4354 (GUA); Dunas do Peró, 21.XII.1982, D.S.D.Araujo 5317 (GUA); Restinga de Massambaba, 24.VI.1987, D.S.D.Araujo 7891 (GUA); Parati, Estrada para a Praia de Trindade, 27.9.2009, M.D.M.Vianna Filho 2017 (RB); Praia de Fora 12.V.1881, A.Glaziou 13214 (P); Rio de Janeiro, Restinga de Itapeba, 22.V.1963, J.P.P.Carauta 179 (GUA, IAN); Botafogo, em direção à Ladeira do Leme, 10.I.2000, B.E.Diaz 189 (GUA); Urca, 6.III.2000, B.E.Diaz 230 (GUA); cultivado no Jardim Botânico, 1917, Dionysio 369 (RB); Praia Vermelha, 21.VII.2012, L.C.Pederneiras 751 (SP); Corcovado, 

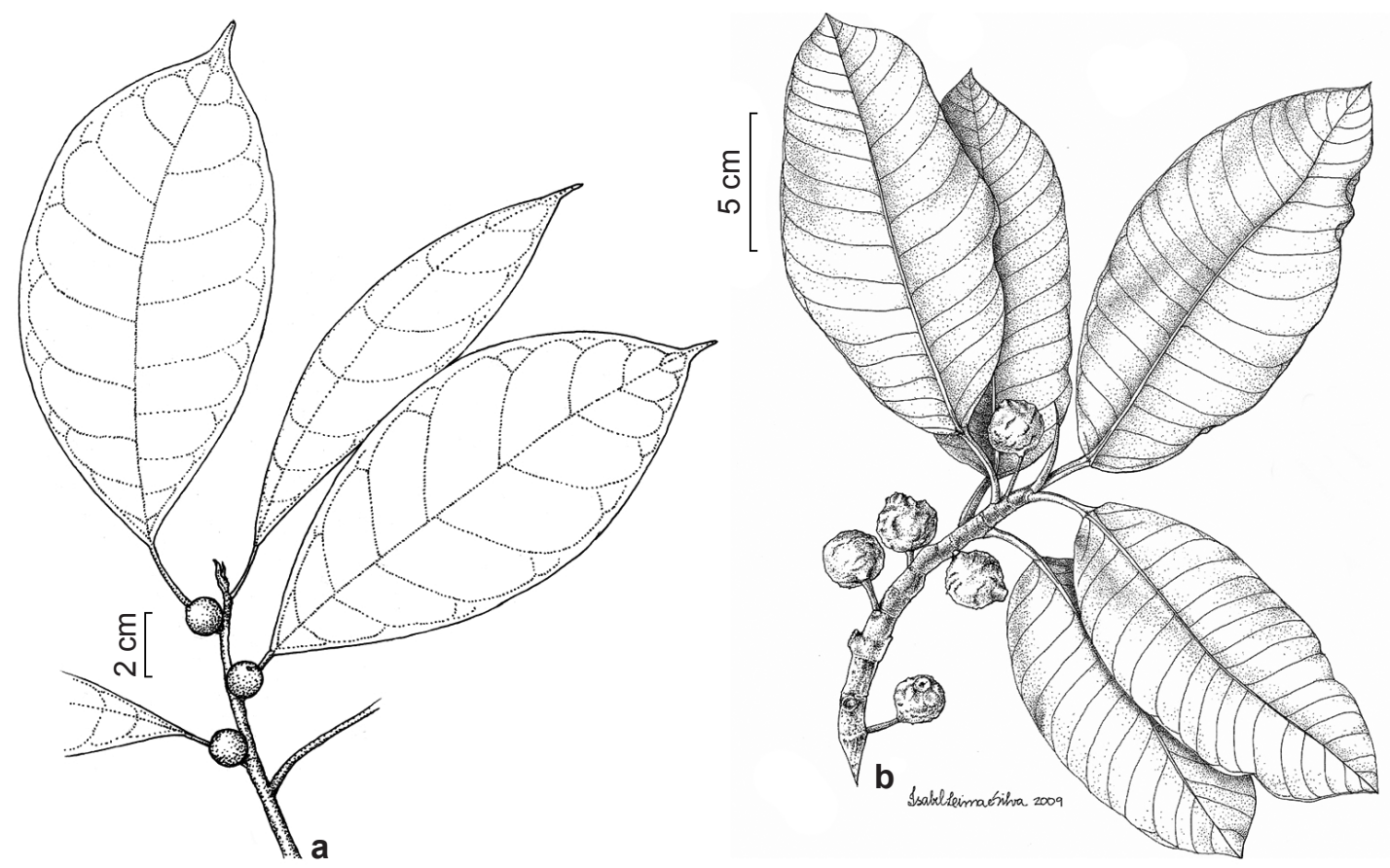

Figura 3 - Ramo com folhas, sicônios e estípulas - a. Ficus ulei; b. Ficus vermifuga (Pederneiras et al. (2011). Figure 3 - Twig with leave, syconia and stipules - a. Ficus ulei; b. Ficus vermifuga (Pederneiras et al. (2011).

28.V.1863, A.Glaziou 763 (P); Baixada de Jacarepaguá, 8.III.1977, D.S.D.Araujo 1534 (GUA, K); Jacarepaguá, 11.IX.1968, J.P.Lanna Sobrinho 1771 (GUA); próximo ao Recreio dos Bandeirantes, 4.IV.1964, W.Hoehne 5725 (SP); Corcovado, III.1873, A. Glaziou 6007 (K, P); Barra da Tijuca, Lagoa de Jacarepaguá, 8.VI.1987, H.C.Lima 6523, 6527 (RB); Corcovado, 24.IX.1893, A.Glaziou (P); Jacarepaguá, 27.X.1987, L.C.Gurken (GUA); Leblon, 8.VIII.1926, J.G.Kuhlmann (RB, US); Morro Dois Irmãos, 19.I.1926, J.G.Kuhlmann (K, RB, US); Saquarema, Jaconé, 18.IV.1992, D.S.D.Araujo 9610 (GUA); Restinga da Tijuca, 14.VI.1969, T.Plowman 2921 (F, GH, K); 12.V.1881, A.Glaziou 13214 (K, P).

Miquel (1848) designou Ficus vermifuga indicando, como tipo, um espécime do herbário de Martius que estava determinada como $F$. anthelmintica, de procedência do Morro do Corcovado, Rio de Janeiro ("Sebastianopolin"), Brasil, coletada entre os meses de setembro a outubro (sem ano). Esse tipo foi encontrado na coleção do herbário de Munique com a seguinte anotação "Ficus -n. 178. Obs., Arbol Magn.”. Analisando o caderno de campo de Martius (1817), está descrito que Ficus vermifuga possuía o receptáculo globoso, rugoso, glabro, com ápice crateriforme "Recept. globosa ragosa, glabra ápice pertusa.”. Estes caracteres são os diagnosticados para o epíteto $F$. nevesiae, e que agora deve ser tratada como $F$. vermifuga.
Ficus vermifuga foi sinonimizado como F. adhatodifolia (Berg \& Villavicencio 2004, "F. nevesiae"), mas aquela difere desta pelo receptáculo: forma (elipsoide e crateriforme $v s$. esferoide e arredondado a obtuso) e superfície (verrucosa vs. lisa).

\section{Agradecimentos}

Agradecemos à FAPERJ, a bolsa do Programa de Pós-Graduação Nota 10 e bolsa de Bancada PDR10-2016 (FAPERJ, E-26/202.862/2016 and $n^{\circ}$ E-26/202.863/2016) concedidas a Leandro Cardoso Pederneiras.

\section{Referências}

Berg, C.C. 2007. New species of Ficus (Moraceae) from South America. Blumea 52: 569-594.

Berg, C.C.; Vazquez-Avila, M. \& Kooy, F. 1986 [1984]. Ficus species of Brazilian Amazonia and the Guianas. Acta Amazonica 14:159-194.

Berg, C.C. \& Villavicencio, X. 2004. Taxonomic studies on Ficus (Moraceae) in the West Indies, extraAmazonian Brazil and Bolivia. Ilicifolia 5: 1-173.

Carauta, J.P.P. 1989. Ficus (Moraceae) no Brasil: conservação e taxonomia. Albertoa 2: 1-365.

Carauta, J.P.P \& Diaz, B.E. 2002. Figueiras no Brasil. Editora UFRJ, Rio de Janeiro. 212p. 
DeWolf, G.P. 1964. Revision of Ficus in extra-tropical South America Paraguay, Uruguay, Argentina \& Southern Brasil (Rio Grande do Sul, Santa Catarina, Paraná). Elliottia 2: 1-15.

DeWolf, G.P. 1965. Ficus, subgenus Pharmacosycea in America. Elliottia 4: 1-20.

Glaziou, A.F.M. 1913. Plantae Brasiliae centralis a Glaziou lectae. Liste des plantes du Brésil Central recueillies en 1861-1895. Bulletin de la Société Botanique de France 57: 585-661.

Martius, C.F.P. 1817. Observationes Botanicae. Plantae in Itinere Brasiliensi annis 1817-1820. Vol. 1. Biblioteca do Jardim Botânico de Munique, Munique. Pp. 1-760.

Spix, J.B. \& Martius, C.F.P. von. 1831. Reise in Brasilien. Vol. 3. M. Lindauer, Munchen. Pp. 888-1388.

Miquel, F.A.G. 1848. Prodromus monogaphie Ficuum. London Journal of Botany 7: 64-78, 109-116, 221 236, 425-471.
Miquel, F.A.G. 1853. Urticineae. In: Martius, C.F.P. (ed.). Flora brasiliensis. Monachii, Lipsiae, Frid. Fleischer. Vol. 4, pars 1, pp. 78-106.

Miquel, F.A.G. 1867. Annotationes de Ficus speciebus. Annales Musei Botanici Lugduno-Batavi 3: 260-315.

Pederneiras, L.C.; Costa, A.F.; Araujo, D.S.D. \& Carauta, J.P.P. 2011. Moraceae das restingas do estado do Rio de Janeiro. Rodriguésia 62: 77-92.

Pederneiras, L.C. \& Romaniuc Neto, S. 2012. Ficus dewolfii (Moraceae), a new species from Colombia. Systematic Botany 37: 684-687.

Pederneiras, L.C.; Carauta, J.P.P. \& Romaniuc Neto, S. 2012. Ficus sect. Pharmacosycea (Moraceae) do Brasil, chave e comentários. Albertoa, ser. Urticineae 37: 285-288.

Radford, A.E. 1986. Fundamentals of plant systematics. Harper and Row, New York. Pp. 1-498.

Schott, H. 1827. Fasciculus plantarum brasiliensium. In: Sprengel, C.P.J. $16^{\mathrm{a}}$ ed. Systema vegetabilium 4: 409-410. 